\title{
Parasympathetic cardio-regulation during social interactions in individuals with obesity-The influence of negative body image
}

\author{
Anne Schrimpf $^{1}$ - Jana Kube ${ }^{1,2}$ - Jane Neumann ${ }^{1,2}$ • Annette Horstmann ${ }^{1,2}$. \\ Arno Villringer ${ }^{1,2,3,4}$ - Michael Gaebler ${ }^{1,4,5}$
}

Published online: 30 November 2016

(C) Psychonomic Society, Inc. 2016

\begin{abstract}
Individuals with obesity in Western societies often face weight-related stigmatization and social exclusion. Recurrent exposure to prejudice and negative social feedback alters one's behavior in future social interactions. In this study, we aimed to investigate autonomic nervous system and affective responses to social interactions in individuals with obesity. Women and men with $(n=56)$ and without $(n=56)$ obesity participated in episodes of social inclusion and social exclusion using a virtual ball-tossing game. During the experiment, heart rate was measured and parasympathetic activity (overall high-frequency power and event-related cardiac slowing) was analyzed. Our results show that in novel social interactions, women with obesity, relative to the other groups, exhibited the strongest increase in parasympathetic activity. Furthermore, parasympathetic activity was related to a more negative body image in individuals with obesity, but not in lean individuals.
\end{abstract}

Electronic supplementary material The online version of this article (doi:10.3758/s13415-016-0482-8) contains supplementary material, which is available to authorized users.

Anne Schrimpf

schrimpf@cbs.mpg.de

1 Department of Neurology, Max Planck Institute for Human Cognitive and Brain Sciences, Stephanstraße 1a, 04103 Leipzig, Germany

2 IFB Adiposity Diseases, Leipzig University Medical Center, Leipzig, Germany

3 Clinic of Cognitive Neurology, University Hospital Leipzig, Leipzig, Germany

4 Berlin School of Mind and Brain, Humboldt-University, Berlin, Germany

5 Leipzig Research Center for Civilization Diseases (LIFE), Leipzig University, Leipzig, Germany
Additionally, women with obesity reported a stronger decrease in mood after social exclusion than did the other participants. Our results demonstrate influences of objective and subjective bodily characteristics on parasympathetic cardioregulation during social interactions. In particular, they show behavioral and physiological alterations during social interactions in women with obesity.

Keywords Obesity $\cdot$ Social information processing $\cdot$ Heart rate variability $\cdot$ Body image $\cdot$ Social exclusion

Human beings are a distinctly social species and strongly dependent on social relationships (Baumeister \& Leary, 1995). However, throughout history and around the world, humans are also engaged in socially excluding and discriminating against other groups, subgroups, or individuals that are deviating from group-specific norms, values, or physical appearance (Kurzban \& Leary, 2001). Individuals of those groups possess an attribute that does not meet society's normative expectations, which can result in a stereotypical classification, and further in social exclusion and stigmatization (Goffman, 1963). Moreover, the visibility and preventability of this attribute enhances stigmatizing behavior (Kurzban \& Leary, 2001; Weiner, Perry, \& Magnusson, 1988).

Being obese in a present Western society is often accompanied by weight-related stigmatization, discrimination, and social exclusion in multiple daily contexts: Individuals with excess weight are judged more negatively, have fewer opportunities on the labor market (Puhl \& Brownell, 2001), and are frequently exposed to teasing and stigmatization in significant interpersonal relationships (Puhl, Moss-Racusin, Schwartz, \& Brownell, 2008). These effects are more prominent in women than in men with obesity (Puhl, Moss-Racusin, \& Schwartz, 2007). Excess body weight is perceived to be under the 
individual's control (DeJong, 1980) and is associated with laziness, irresponsibility, lack of intelligence, or self-control (Crandall, 1994; Puhl \& Brownell, 2001) —which are highly undesirable traits in modern, performance-oriented societies. Additionally, Andreyeva, Puhl, and Brownell (2008) showed that weight stigmatization is rising disproportionally with obesity rates, indicating a further growing negative bias against individuals with obesity.

It has been hypothesized that recurrent negative social experiences change one's behavior in future social interactions. Swim, Cohen, and Hyers (1998) argued that stigmatized individuals are able to anticipate potentially stigmatizing situations. The targets of peer victimization show increased vigilance toward even subtle cues of prejudice. The pure anticipation of being the target of prejudice increases attention to the signs of devaluation (Kaiser, Vick, \& Major, 2006), and fear of negative evaluation enhances attention to threat cues after social exclusion (Tanaka \& Ikegami, 2015). Improved detection accuracy of prejudice enables individuals to apply strategies that prevent or reduce its negative impact on psychological well-being (Barreto \& Ellemers, 2015). Such strategies comprise psychological disengagement (Crocker \& Major, 1989), avoidance (Puhl \& Brownell, 2003), and assertion or aggression (Joanisse \& Synnott, 1999), as well as compensation with increased prosocial behavior (Miller, Rothblum, Felicio, \& Brand, 1995). Furthermore, it has been shown that, in the presence of negative stereotypical statements, individuals are more likely to show disengagement after negative feedback (Leitner, Jones, \& Hehman, 2013). These studies have indicated two, complementary mechanisms of behavioral adaption to social exclusion: (1) heightened vigilance to social cues in situations in which an individual has previously experienced negative feedback (Kaiser et al., 2006; Tanaka \& Ikegami, 2015), and (2) the application of coping mechanisms like disengagement in an actual discriminatory situation (Leitner et al., 2013).

Blackhart, Nelson, Knowles, and Baumeister (2009) found that experimentally excluded participants not only showed altered vigilance for social cues but also reported more negative affect than included participants, indicating the potential detrimental effects of exclusion on well-being. In participants with obesity, social exclusion furthermore increased the feeling of shame (Westermann, Rief, Euteneuer, \& Kohlmann, 2015). Shame has been described as a feeling of being worthless and might result in withdrawal or maladaptive coping in stressful situations (Conradt et al., 2008). Body shame has been found to be related to disordered eating and depressive symptoms (Tiggemann \& Kuring, 2004). Moreover, body shame mediates the relationship between weight status and self-esteem (Pila, Sabiston, Brunet, Castonguay, \& O'Loughlin, 2015). In individuals with obesity, increased shame after social exclusion might contribute to a higher prevalence of psychological disorders described in the literature (Carpenter, Hasin, Allison, \& Faith, 2000).
Psychophysiological and neuroimaging studies on social exclusion support the psychological processes involvedsuch as attention, regulation, or negative affect: Functional MRI studies have shown brain activation associated with social exclusion in the anterior cingulate cortex and the ventrolateral prefrontal cortex - areas associated with distress and conflict monitoring (Botvinick, Cohen, \& Carter, 2004; Eisenberger, Lieberman, \& Williams, 2003). This effect was more pronounced in individuals with more experiences of childhood peer rejection (Will, van Lier, Crone, \& Güroğlu, 2015). Psychophysiological studies on social interactions have examined the arousal and activation of the autonomic nervous system (ANS), for example by using heart rate (HR) recordings. The ANS influences heart activity by input to the sinoatrial node. A particular focus thereby lies on the interplay of the fast-responding inhibitory parasympathetic nervous system (PNS) and the slow-responding excitatory sympathetic nervous system (SNS). PNS activation is typically measured as rapid changes in HR and increased heart rate variability (HRV). According to the "neurovisceral integration model," higher PNS activity indexes physiological and behavioral flexibility to changing environmental demands (Thayer \& Lane, 2000, 2009). This framework thus connects affective and attentional processes to the ANS. Of particular interest for this study are social factors influencing HRV or PNS activation: Patients with social anxiety disorder show decreased HRV - an index of decreased PNS activity at rest (Alvares et al., 2013) and during implicit emotional face processing (Gaebler, Daniels, Lamke, Fydrich, \& Walter, 2013). In healthy participants, HRV has been shown to decrease during psychosocial stress and other negative social interactions (Shahrestani, Stewart, Quintana, Hickie, \& Guastella, 2015).

On the other hand, Gunther Moor, Crone, and van der Molen (2010) showed that when participants received unexpected social rejection, the heart period decelerated, indicating increased PNS activity. A similar effect was found in adolescents (Gunther Moor, Bos, Crone, \& van der Molen, 2014) as well as after laughter stimuli in individuals that perceived laughter as a cue of social rejection (Papousek et al., 2014). Conversely, during an episode of exclusion relative to an episode of inclusion, an increase in tonic HR (Iffland, Sansen, Catani, \& Neuner, 2014a; Murray-Close, 2011) and a reduction of PNS-driven respiratory sinus arrhythmia (Murray-Close, 2011) have been observed. Since HR is controlled by a complex interplay between the PNS and SNS, the relative impact of PNS and SNS activity on HR changes cannot be fully disentangled. Similarly, Newman (2014) showed that social exclusion correlates with increased sympathetic activity measured through pre-ejection period, an association that was blunted in individuals with previous victimization. In summary, social, attentional, and affective processes have been associated with changes in PNS 
activity. Although negative or stressful information processing was associated with decreases in HRV, regulatory processes have been related to increased HRV.

As we mentioned above, studies have suggested that targets of victimization adaptively respond to potentially threatening social situations with higher vigilance and, when receiving negative feedback, with psychological disengagement. However, there has been little research into how people with obesity or stigmatizing experiences process and respond to new social situations or social exclusion. In a previous study, we found that women with obesity showed slower response times than did lean women during the anticipation of social as compared to monetary feedback, as well as blunted cardiac responses to negative social stimuli. This differential response was more pronounced in women with obesity with higher body mass indexes (BMIs) and more intense weight-related teasing experiences (Kube, Schrimpf, et al., 2016).

In the present study, we aimed to investigate the ANS and affective responses to social interaction in individuals with obesity. We applied the well-established Cyberball paradigm (Williams, Cheung, \& Choi, 2000), a virtual balltossing game, to induce standardized episodes of social inclusion and exclusion. To establish a potentially threatening or stigmatizing social situation, the participant's full-body picture was visible throughout the experiment. During the entire experiment, each participant's electrocardiogram (ECG) was recorded, and changes in heart periods as well as HRV were analyzed. Since the heart is under constant inhibitory control by the PNS, fast phasic changes in heart periods and measures of HRV mainly reflect parasympathetic (or vagal) cardio-regulation (e.g., Thayer \& Lane, 2000). For phasic heart period changes, it has been shown that motivationally relevant stimuli-in particular, negatively valenced stimuli-elicit an immediate cardiac deceleration followed by a delayed acceleratory recovery (Somsen, Van der Molen, Jennings, \& van Beek, 2000; van der Veen, van der Molen, Crone, \& Jennings, 2004). The analysis of HRV in the frequency domain allows the extraction of PNS or vagal activity through the quantification of power in the high-frequency (HF) band between 0.15 and $0.40 \mathrm{~Hz}$ (HF power). Increased HRV during experimental conditions, indexing parasympathetic cardio-regulation, has been associated with attentional engagement, emotional self-regulation, or-more generally-behavioral flexibility (Porges, 2007; Thayer \& Lane, 2000, 2009).

On the basis of the existing literature, we hypothesized that individuals with obesity, as compared to lean individuals, would show a higher vigilance to potentially threatening social cues and exhibit stronger parasympathetic activation when engaging in a novel social interaction, in which they are included but their weight status is visible. However, when confronted with social exclusion by others, we assumed that individuals with obesity and with a history of weight-related stigmatization would show parasympathetic withdrawal, indicated by a blunted phasic heart period response and lower HRV. Additionally, we hypothesized that social exclusion would affect individuals with obesity more negatively than lean individuals, as indicated through worse mood, happiness, or a lower feeling of being accepted. Finally, we examined possible influencing factors such as sex, negative body image, and social insecurity, which we expected to alter the responses to social interactions. We hypothesized that the effects of inclusive and exclusive social interactions would be more pronounced in women than in men with obesity and that negative body image as well as social insecurity would modulate the weight-related influence on social information processing.

\section{Method}

\section{Participants}

Participants were recruited from the database of the Max Planck Institute for Human Cognitive and Brain Sciences, Leipzig, Germany. Volunteers either entered their details into the database via the Institute's website or were recruited for previous studies via advertisement in public spaces. A total of 120 healthy individuals, matched for educational background and age, participated in this study. The inclusion criteria were that participants be between 18 and 35 years of age and have BMIs $>30.0 \mathrm{~kg} / \mathrm{m}^{2}$ for obese or between $18.5 \mathrm{~kg} / \mathrm{m}^{2}$ and $24.9 \mathrm{~kg} / \mathrm{m}^{2}$ for lean control participants, respectively. All participants underwent a telephone screening and were excluded when meeting any of the following exclusion criteria: history of neuropsychiatric disorders, hypertension, respiratory or thyroid diseases, smoking, and regular substance or medication use. Eight individuals were excluded after participation: three due to a total score above 18 on the Beck Depression Inventory (BDI; Beck, Steer, \& Carbin, 1988), one due to previously unreported occasional smoking, two due to data-recording failure, and two due to deviating $\mathrm{HR}$ responses (more than three interquartile ranges from the nearer edge of the boxplots). Thus, 112 participants entered the final analyses: 29 lean women (age $=26.5 \pm$ 3.8 years, $\mathrm{BMI}=21.6 \pm 2.0$ ), 29 women with obesity (age $=$ $26.2 \pm 3.7$ years, $\mathrm{BMI}=36.1 \pm 4.9), 27$ lean men $($ age $=27.2 \pm$ 3.3 years, $\mathrm{BMI}=22.1 \pm 1.5$ ), and 27 men with obesity (age $=$ $27.9 \pm 3.1$ years, $\mathrm{BMI}=35.1 \pm 3.8$ ).

All participants gave written informed consent and received a reimbursement for their participation $(€ 7 / \mathrm{h})$. The study duration was a total of 3-4 h on two separate days. The study was carried out in accordance with the Declaration of Helsinki and was approved by the ethics committee of the Leipzig University. 


\section{Procedure}

All participants were invited on two separate days within one week. During the first appointment, participants completed questionnaires assessing their demographic information, body image, stress, depression, and rejection sensitivity. Then weight, height, and waist and hip circumference were measured before a full-body photo was taken of each participant. Here, participants were asked to wear a slimfitting black shirt and leggings provided by us to take a portrait in front of a white background. On the second day, participants took part in the Cyberball paradigm, a virtual ball-tossing game to induce a standardized social exclusion experience (Williams et al., 2000). Participants were randomly assigned to either the inclusion or the exclusion condition. They were instructed by the experimenter that two other invited participants were sitting in nearby rooms and would play an online game with the participant. In reality, the two players were computer generated. All players were represented on the computer screen by drawings and a full-body picture. The participant's character and picture were located at the bottom center of the screen (see Fig. 1). The two confederates had the same sex as the participant. To induce a potentially stigmatizing situation, the pictures of the computer-generated players had lean body shapes. Photographs of the two female and two male lean players were taken of coworkers at the institute.

Before the start of the experiment, participants completed initial visual analogue scales (VASs) to assess their baseline mood, happiness, and feelings of being accepted (see Table 1). Afterward, the ECG electrodes were attached (see below for details). Before the start of the experiment, a 4-min

A
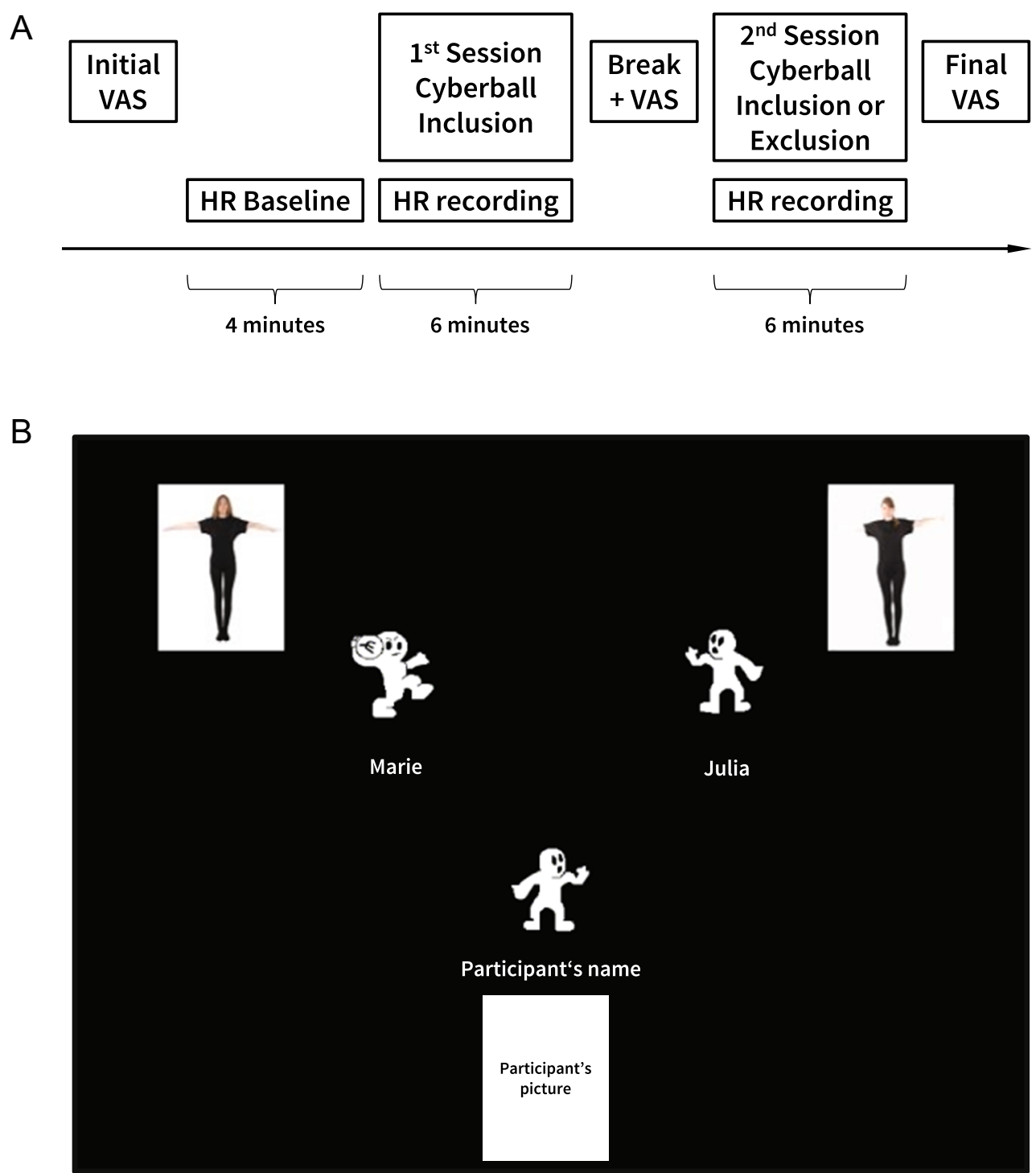

Fig. 1 Paradigm. (A) Overall experimental timeline. (B) The participant and the two confederates were represented on the computer screen by drawings, a full-body picture and their names, with the participant's character, picture, and name located at the bottom center 
Table 1 Sample characteristics

\begin{tabular}{|c|c|c|c|c|c|c|c|c|}
\hline & $\begin{array}{l}\text { Lean Women } \\
n=29\end{array}$ & $\begin{array}{l}\text { Women With Obesity } \\
n=29\end{array}$ & Lean Men $n=27$ & $\begin{array}{l}\text { Men With Obesity } \\
n=27\end{array}$ & Weight & & Weight & Sex \\
\hline$n$ Incl./Excl. & $15 / 14$ & $15 / 14$ & $14 / 13$ & $13 / 14$ & $F$ & $p$ & $F$ & $p$ \\
\hline \multicolumn{9}{|l|}{ Anthropometrics } \\
\hline Age & $26.45 \pm 3.8$ & $26.17 \pm 3.7$ & $27.15 \pm 3.3$ & $27.89 \pm 3.1$ & 0.145 & .704 & 0.578 & .449 \\
\hline Education in years & $15.62 \pm 1.6$ & $15.28 \pm 1.5$ & $15.85 \pm 1.8$ & $14.96 \pm 1.2$ & 0.113 & .738 & 0.113 & .738 \\
\hline BMI & $21.64 \pm 2.0$ & $36.11 \pm 4.9$ & $22.06 \pm 1.5$ & $35.09 \pm 3.8$ & 465.811 & .001 & 1.252 & .266 \\
\hline WHR & $.73 \pm 0.05$ & $.82 \pm 0.07$ & $.81 \pm 0.04$ & $.97 \pm 0.07$ & 126.855 & .001 & 10.185 & .002 \\
\hline Sports h/week & $3.59 \pm 3.5$ & $2.84 \pm 3.5$ & $4.14 \pm 3.7$ & $4.02 \pm 3.2$ & 0.397 & .530 & 0.249 & .619 \\
\hline \multicolumn{9}{|c|}{ Components derived from questionnaires } \\
\hline Insecurity & $-.07 \pm 0.9$ & $.03 \pm 1.1$ & $.31 \pm 1.1$ & $-.26 \pm 0.9$ & 1.685 & .197 & 3.365 & .069 \\
\hline Negative body image & $-0.33 \pm 0.5$ & $\mathbf{1 . 0 8} \pm 0.6$ & $-1.17 \pm 0.3$ & $0.37 \pm 0.8$ & 214.562 & .001 & 0.251 & .618 \\
\hline Perceived overload & $.32 \pm 1.2$ & $-.10 \pm 1.0$ & $-.04 \pm 0.7$ & $-.19 \pm 1.0$ & 2.159 & .145 & 0.497 & .483 \\
\hline \multicolumn{9}{|c|}{ Visual analogue scales baseline } \\
\hline Mood (mm) & $7.53 \pm 1.3$ & $7.47 \pm 1.4$ & $7.17 \pm 1.5$ & $7.67 \pm 1.2$ & 0.726 & .396 & 1.144 & .287 \\
\hline Happiness (mm) & $6.85 \pm 1.4$ & $6.63 \pm 1.2$ & $6.71 \pm 1.5$ & $6.87 \pm 1.1$ & 0.009 & .926 & 0.628 & .430 \\
\hline Feeling of acceptance (mm) & $8.14 \pm 1.4$ & $7.72 \pm 1.5$ & $7.15 \pm 1.3$ & $7.83 \pm 1.2$ & 0.245 & .621 & 4.712 & .032 \\
\hline \multicolumn{9}{|l|}{ Heart rate variability baseline } \\
\hline Mean HR (bpm) & $79.45 \pm 10.4$ & $79.39 \pm 8.6$ & $79.18 \pm 11.2$ & $77.63 \pm 8.8$ & 0.287 & .593 & 0.194 & .661 \\
\hline LF power $\left(\mathrm{ms}^{2}\right)$ & $959 \pm 728$ & $1,418 \pm 1,129$ & $1,583 \pm 1,262$ & $1,347 \pm 1,343$ & 0.282 & .597 & 2.644 & .107 \\
\hline HF power $\left(\mathrm{ms}^{2}\right)$ & $631 \pm 826$ & $1,447 \pm 4,432$ & $589 \pm 985$ & $747 \pm 1081$ & 1.097 & .297 & 0.473 & .493 \\
\hline HF power n.u. & $35.37 \pm 21.8$ & $32.95 \pm 21.1$ & $22.64 \pm 13.0$ & $31.45 \pm 18.1$ & 0.874 & .352 & 2.440 & .121 \\
\hline LF/HF power $\left(\log _{10}\right)$ & $.31 \pm 0.5$ & $.37 \pm 0.5$ & $.59 \pm 0.3$ & $.41 \pm 0.4$ & 0.685 & .410 & 1.993 & .161 \\
\hline
\end{tabular}

Univariate ANCOVAs: BMI = body mass index, WHR = Waist-to-hip-ratio, $\mathrm{HR}=$ heart rate, $\mathrm{LF}=$ low-frequency power, $\mathrm{HF}=$ high-frequency power, $\mathrm{HF}$ power n.u. $=$ normalized units, $\mathrm{LF} / \mathrm{HF}=$ ratio between $\mathrm{LF}$ and $\mathrm{HF}$ power. Values represent means $\pm S D$ s, and boldface indicates results significant at $p<.05$

HR measurement at rest was acquired. This was followed by two 6-min sessions of the Cyberball game. In the first session, all participants were included in the game, whereas in the second session, $50 \%$ were included as before, and $50 \%$ were excluded. With a computer mouse, participants were able to throw the ball to the confederates. The first session consisted of approximately 150 ball throws, of which the participant received one third - that is, every player received the ball equally often throughout the game. Each trial of the computergenerated players lasted between 1,600 and 4,600 ms, consisting of a randomized waiting period (1,000 to $4,000 \mathrm{~ms})$ and a "throw and flight" period $(600 \mathrm{~ms})$.

The first session ended with a short break, during which participants completed a second set of VASs to assess their mood, happiness, and feelings of being accepted. In the second session of the game, one group of participants continued to be included in the game, as before. A second group of participants underwent the exclusion condition, in which they received just one ball per minute after the first three throws. This resulted in approximately seven ball tosses during the $6 \mathrm{~min}$ (as compared to $\sim 50 \mathrm{~min}$ in the inclusion condition). At the end, participants completed a final set of VASs to one again measure mood, happiness, and feelings of being accepted. All participants were debriefed at the end of the experiment.

\section{Psychometric measures and factor analysis}

On the first day of the experiment, all participants completed a battery of questionnaires to assess study-relevant information about the individuals' personality traits, body image, stress, and depression: the BDI (Beck et al., 1988), Body Image Avoidance Questionnaire (BIAQ; Legenbauer, Vocks, \& Schütt-Strömel, 2007), Body Shape Questionnaire (BSQ; Cooper, Taylor, Cooper, \& Fairbum, 1987), Eating Disorder Inventory (EDI-2; Garner, 1991), Fear of Negative Evaluation Scale (SANB-5; Kemper, Lutz, \& Neuser, 2012), Figure Rating Scales (FRS; Stunkard, Sorensen, \& Schulsinger, 1983), NEO Five-Factor Inventory (NEO-FFI; Borkenau \& Ostendorf, 1993), Perceived Stress Questionnaire (PSQ-20; Fliege, Rose, Arck, Levenstein, \& Klapp, 2001), Perceived Stress Scale (PSS-10; Cohen, Kamarck, \& Mermelstein, 1983), Perception of Teasing Scale (POTS; Thompson, Fabian, Moulton, Dunn, \& Altabe, 1991), Rejection Sensitivity Questionnaire (RSQ; Staebler, Helbing, Rosenbach, \& Renneberg, 2011), Rosenberg Self-esteem Scale (RSES; Rosenberg, 1965), and Trier Inventory for Chronic Stress (TICS; Schulz \& Schlotz, 1999).

A principal component analysis (PCA) with orthogonal rotation (varimax) was conducted using IBM SPSS Statistics 
23 (Armonk, NY, USA) to reduce the number of variables and extract convergent latent factors across different measures of self-related social experiences. Only the total scores of the questionnaires or specific subscales that assessed social contexts and fulfilled the criteria for PCA were included. The Kaiser-Meyer-Olkin (KMO) measure of .86 (with all KMO values for individual scales $>.62$ and thus above the threshold of .5) confirmed the sampling adequacy for the analysis. The correlations between scales were sufficiently large for a PCA [Bartlett's test of sphericity: $\chi^{2}(406)=2296.256, p<.001$ ]. In the initial analysis, six components had eigenvalues over 1 (Kaiser's criterion) and explained $69.08 \%$ of the variance. The scree plot was showing inflexions that justified retaining three components (explaining $57.06 \%$ of the variance). After evaluation of the scales that clustered on the same component, Component 1 was summarized as social insecurity, Component 2 as negative body image, and Component 3 as perceived overload (see Table $\mathrm{S} 1$ in the supplements).

\section{HR data recordings and analysis}

A three-lead ECG was continuously recorded during both parts of the experiment, each lasting for $6 \mathrm{~min}$, and during the 4-min resting period before the start. The ECG data were recorded at $500 \mathrm{~Hz}$ using a BrainAmp ExG amplifier and BrainVision Recorder software (Version 1.20.0506, Brain Products, München, Germany). Three $\mathrm{Ag} / \mathrm{AgCl}$ electrodes (MES Forschungssysteme GmbH, Gilching, Germany) were placed between the right clavicle and sternum, on the left side between the two lower rips, and on the right lower abdomen.

The ECG data were imported into Kubios (Version 2.2; Biosignal Analysis and Medical Imaging Group, University of Eastern Finland, http://kubios.uef.fi/) and visually inspected. For unclear peaks, the Kubios artifact correction level "very low" was applied that identifies and (cubic spline) interpolates RR intervals that are differing more than $0.45 \mathrm{~s}$ from the local mean RR interval. The amount of corrected peaks did not exceed $0.5 \%$ of the total analyzed data and artifact correction was equally distributed in subsamples; that is, there was no significant difference between groups in number of corrected peaks [interaction of Weight $\times$ Sex, $F(3$, $108)=1.38, p=.252]$. We analyzed mean HR and HRV in the frequency domain, the latter by means of fast Fourier transformation using Welch's periodogram method with a sliding window of $256 \mathrm{~s}$ and $50 \%$ overlap. In particular, we extracted low-frequency (LF; 0.04-0.15 Hz) and HF (0.15$0.4 \mathrm{~Hz}$ ) power. $\mathrm{LF}$ and $\mathrm{HF}$ power were analyzed in normalized units (n.u.) by dividing the values through the total LF and HF power. Normalization removes unequal distribution of the raw data and increases comparability between individuals and studies (Burr, 2007). Because of the linear redundancy between LF n.u. and HF n.u. (Burr, 2007), and because HF power is more clearly interpretable as parasympathetic activation (Billman, 2013; Thayer \& Lane, 2000), we will only report HF power n.u. in the following results section. All raw HRV values for baseline and experimental sessions can be found in supplements (Table S2 in the supplements).

For our event-related heart period analyses, in-house MATLAB scripts (MATLAB R2016a; The MathWorks, Sherborn, MA, USA) extracted event-related interbeat intervals (IBIs) from the files that were previously corrected with Kubios. Five consecutive IBIs around event onset were extracted. The events were ball tosses between computergenerated players, tosses to the participant, and participant's tosses. To avoid an interference with the participant's motor response (Jennings \& van der Molen, 2002), only the ball tosses between the computer-generated players were included in the analysis. To account for a few deviant trials and to increase robustness of analysis, the median of each participant's IBIs was used for further analysis. IBI0 was measured at the time of the ball throw. In addition, one IBI prior to the ball-tossing (IBI-1), and two IBIs following the ball-tossing (IBI+1, IBI+2) were included in the analysis. All IBIs were referenced to the baseline IBI (IBI-2), at which no significant effects of time, sex, weight, or condition emerged $[$ Time $\times$ Weight $\times$ Sex $, F(1,104)=0.464, p=.497$; Time $\times$ Weight $\times$ Sex $\times$ Condition, $F(1,104)=0.992, p=.321]$. Furthermore, there were no significant effects of time, sex, weight, or condition on IBI-1 [Time $\times$ Weight $\times$ Sex, $F(1$, $104)=1.297, p=.257$; Time $\times$ Weight $\times$ Sex $\times$ Condition, $F(1,104)=0.359, p=.550]$.

\section{Statistical analysis}

All statistical analyses were carried out using IBM SPSS Statistics 23 (Armonk, NY, USA) with a two-sided $\alpha$ level of .05. Greenhouse-Geisser corrections were used to adjust the degrees of freedom in mixed-design analyses of variance (ANOVAs) in case the assumption of sphericity was violated according to the Mauchly test. In this case, we report uncorrected degrees of freedom, corrected $p$ values, and epsilon $(\varepsilon)$. Estimated effect sizes are reported using partial eta squared $\left(\eta_{\mathrm{p}}{ }^{2}\right)$. The mean-centered covariate "age" was included in all mixed-design analyses of covariance (ANCOVAs). All reported post-hoc results were least significant difference corrected.

Group differences in the participant characteristics and baseline HRV data were analyzed using univariate ANCOVAs, employing between-subjects factors "weight" (lean, obese), "condition" (inclusion, exclusion), and "sex" (women, men). VAS changes over time were analyzed using separate mixeddesign ANCOVAs for all time points, employing the withinsubjects factor Time (baseline, 1st session, 2nd session) and the between-subjects factors Condition (inclusion, exclusion), Weight (lean, obese), and Sex (women, men). HRV changes from baseline to the first session and HRV changes from the first to the second experimental session were examined 
separately in order to disentangle general effects of social interaction from social exclusion. Mixed-design ANCOVAs for all time points were used, employing the within-subjects factor Time and the between-subjects factors Weight (lean, obese), Sex (women, men), and, for the analysis between the first and second session, Condition (inclusion, exclusion).

Phasic heart period changes between the two experimental sessions were analyzed using a mixed-design ANCOVA with the within-subjects factors Time and IBI, as well as betweensubjects factors Weight (lean, obese), Sex (women, men), and Condition (inclusion, exclusion).

Furthermore, two-sided bivariate correlations were calculated to analyze the associations of HRV and phasic heart period responses with the state and trait variables (VAS and principle components). A Fisher's $r$-to- $z$ transformation was performed to assess group differences between the correlations.

\section{Results}

\section{Group characteristics}

The means and standard deviations for all group characteristics can be found in Table 1. Lean women, lean men, and women and men with obesity did not significantly differ in age, education, and hours of sports per week. In line with our inclusion criteria, the groups significantly differed in BMI [main effect of weight, $F(1,104)=465.811, p<.001, \eta_{\mathrm{p}}{ }^{2}=$ .817] and waist-to-hip-ratio [main effect of sex, $F(1,104)=$ $102.601, p<.001, \eta_{\mathrm{p}}{ }^{2}=.497$; main effect of weight, $F(1,104)$ $=126.855, p<.001, \eta_{\mathrm{p}}{ }^{2}=.549$; interaction of Sex $\times$ Weight, $\left.F(1,104)=10.185, p=.002, \eta_{\mathrm{p}}{ }^{2}=.089\right]$. Regarding the components derived from questionnaires, we found no difference between the groups in social insecurity and perceived overload. However, the groups differed significantly in negative body image [main effect of sex, $F(1,104)=61.113, p<$ $.001, \eta_{\mathrm{p}}{ }^{2}=.370$; main effect of weight, $F(1,104)=214.562, p$ $\left.<.001, \eta_{\mathrm{p}}{ }^{2}=.674\right]$, with women with obesity having the highest and lean men having the lowest negative body image (lean women, $M=-0.33, S D=0.46$; lean men, $M=-1.17, S D$ $=0.32$; women with obesity, $M=1.08, S D=0.56$; men with obesity, $M=0.37, S D=0.79$ ). Although we did not find a correlation between social insecurity, negative body image, and perceived overload in the lean group; social insecurity and negative body image showed a significant positive correlation $[r(56)=.34, p=.010]$ in the group with obesity (Table 2). The baseline HRV parameters did not differ significantly between groups, except for HF power n.u. [main effect of sex, $F(1,104)=4.083, p=.046, \eta_{\mathrm{p}}{ }^{2}=.038$ ], with lower values in men $(M=27.05, S D=16.25)$ than in women $(M=$ $34.16, S D=21.28$ ).

\section{Visual analogue scales}

The analyses over all three measurement times for mood revealed a significant main effect of time $[F(2,206)=5.625, \varepsilon=$ $\left..931, p=.005, \eta_{\mathrm{p}}{ }^{2}=.052\right]$ and a Time $\times$ Condition interaction $\left[F(2,206)=4.029, \varepsilon=.931, p=.022, \eta_{\mathrm{p}}{ }^{2}=.038\right]$. Mood was significantly lower in the second session after exclusion than after inclusion (exclusion $M=6.78, S D=1.7$, inclusion $M=$ $7.43, S D=1.3, p=.019)$. A Time $\times$ Condition $\times$ Sex $\times$ Weight interaction $\left[F(2,206)=3.166, \varepsilon=.931, p=.048, \eta_{\mathrm{p}}{ }^{2}=.030\right]$ showed that only women with obesity exhibited a significant difference in mood after the second session inclusion and the second session exclusion. Women with obesity that were excluded from the ball-tossing game showed more negative $\operatorname{mood}(M=6.28, S D=1.7)$, whereas women with obesity that were further included showed more positive $\operatorname{mood}(M=7.84$,

Table 2 Correlations between principal components in individuals with obesity (upper diagonal) and lean individuals (gray, lower diagonal)

\begin{tabular}{|c|c|c|c|}
\hline & $\begin{array}{c}\text { Social } \\
\text { insecurity }\end{array}$ & $\begin{array}{c}\text { Negative body } \\
\text { image }\end{array}$ & $\begin{array}{c}\text { Perceived } \\
\text { overload }\end{array}$ \\
\cline { 2 - 5 } & $\begin{array}{c}\text { Social } \\
\text { insecurity }\end{array}$ & $\mathbf{. 3 4 2 * *}$ & -.040 \\
\hline $\begin{array}{c}\text { Negative body } \\
\text { image }\end{array}$ &,- 144 & .141 \\
\hline Perceived \\
overload
\end{tabular}


$S D=1.0, p=.005)$. Furthermore, only excluded women with obesity showed a significant decrease in mood from the first to the second experimental condition (mood after first session, $M$ =7.03, $S D=1.6$; mood after second session, $M=6.28, S D=$ 1.7, $p=.019$; Fig. 2).

For happiness, we found a significant main effect of condition $\left[F(1,103)=5.029, \varepsilon=.917, p=.027, \eta_{\mathrm{p}}{ }^{2}=.047\right]$. A Time $\times$ Condition $\times$ Sex $\times$ Weight interaction $[F(2,206)=$ $\left.3.689, \varepsilon=.917, p=.030, \eta_{\mathrm{p}}{ }^{2}=.035\right]$ indicated that women with obesity and lean men reported a significantly lower level of happiness after the second-session exclusion (women with obesity, $M=5.73, S D=1.5$; lean men, $M=6.19$, $S D$ $=1.3$ ), relative to women with obesity and lean men after the second-session inclusion (women with obesity, $M=7.23$,

A

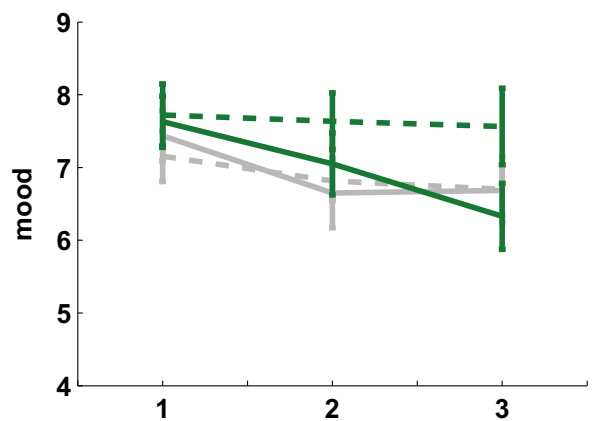

B

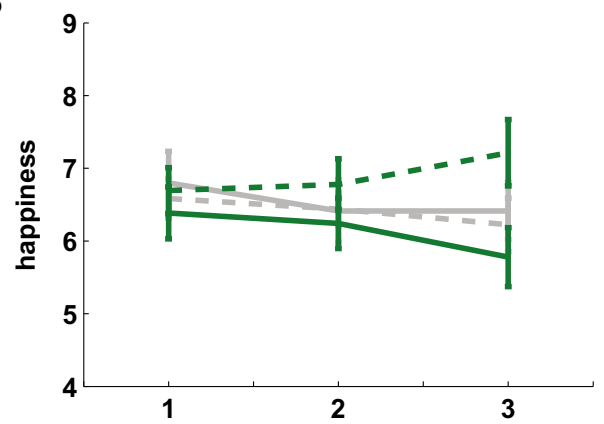

C

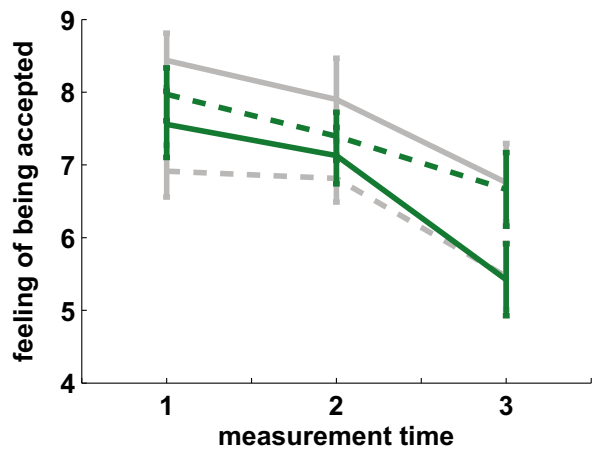

Fig. 2 Visual analogue scales. Values represent means $\pm S E$ s. The rows show changes in $(\mathbf{A})$ mood [Time $\times$ Condition $\times$ Sex $\times$ Weight interaction, $\left.F(2,206)=3.166, \varepsilon=.931, p=.048, \eta_{\mathrm{p}}{ }^{2}=.030\right],(\mathbf{B})$ happiness [Time $\times$ Condition $\times$ Sex $\times$ Weight interaction, $F(2,206)=3.689, \varepsilon=.917, p=.030$,
$S D=1.0, p=.006$; lean men, $M=7.52, S D=1.5, p=.017)$. Furthermore, women with obesity had lower levels of happiness $(M=5.73, S D=1.5)$ than did men with obesity when they were excluded in the second session $(M=7.17, S D=$ 1.7, $p=.009$; Fig. 2).

For the feeling of being accepted, we found a significant main effect of time $\left[F(2,206)=30.193, p<.001, \eta_{\mathrm{p}}{ }^{2}=.227\right]$ and a Time $\times$ Condition interaction $[F(2,206)=22.047, p<$ $\left..001, \eta_{\mathrm{p}}{ }^{2}=.176\right]$, showing that excluded participants felt less accepted after the second session $(M=6.04, S D=1.9)$ than did included participants $(M=7.45, S D=1.3, p<.001)$. A between-subjects interaction of Condition $\times$ Sex $\times$ Weight $\left[F(1,103)=4.657, p=.033, \eta_{\mathrm{p}}{ }^{2}=.043\right]$ indicated that women with obesity and lean men who were excluded from the
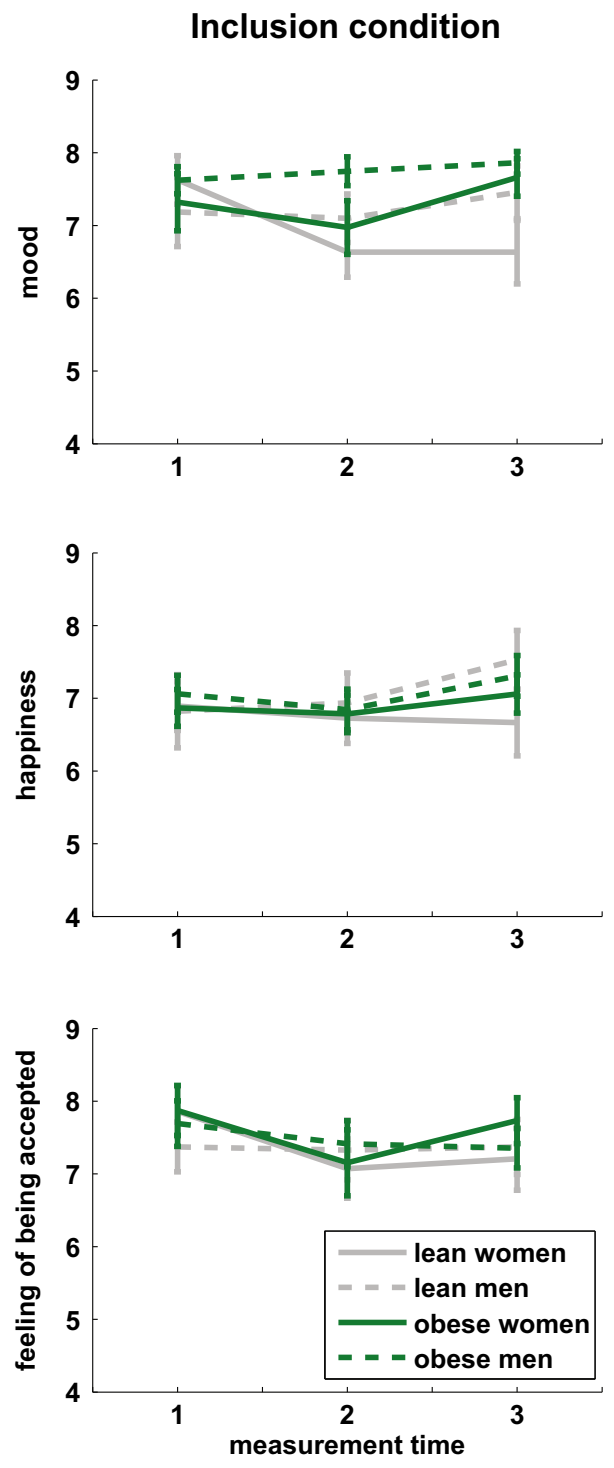

$\left.\eta_{\mathrm{p}}{ }^{2}=.035\right]$, and $(\mathbf{C})$ feelings of being accepted [Condition $\times$ Sex $\times$ Weight interaction, $\left.F(1,103)=4.657, p=.033, \eta_{\mathrm{p}}{ }^{2}=.043\right]$ over time in the exclusion (left) and inclusion (right) conditions 
ball-tossing game felt less accepted than women with obesity and lean men who continued to be included in the game (women with obesity exclusion, $M=6.68, S D=1.4$; inclusion, $M=7.67, S D=1.3, p=.047$; lean men exclusion, $M=$ 6.38, $S D=1.2$; inclusion, $M=7.35, S D=1.3, p=.055$ ). Additionally, in the exclusion condition, women with obesity felt less accepted than lean women (women with obesity, $M=6.68, S D=1.4$; lean women, $M=7.70, S D=1.6, p=$ .041 ; Fig. 2).

\section{Heart rate variability}

Social inclusion: Changes from baseline to the first experimental session The analysis of changes from baseline to the first session for mean $H R$ showed a significant main effect of time $\left[F(1,107)=43.209, p<.001, \eta_{\mathrm{p}}{ }^{2}=.288\right]$. All participants had a decrease in mean HR in the first experimental session $(M=78.93, S D=9.7)$ relative to baseline $(M=76.91$, $S D=9.5)$.

The analysis of the $H F$ power n.u. revealed a significant main effect of time $\left[F(1,107)=45.322, p<.001, \eta_{\mathrm{p}}{ }^{2}=.298\right]$. A Time $\times$ Sex $\times$ Weight interaction $[F(1,107)=8.926, p=$ $\left..003, \eta_{\mathrm{p}}{ }^{2}=.077\right]$ showed that all groups but men with obesity had a significantly increase from baseline to the first session (lean women baseline, $M=34.97, S D=21.8$; first session, $M$ $=43.72, S D=20.4, p=.001$; women with obesity baseline, $M=32.31, S D=21.1$; first session, $M=50.71, S D=16.6, p<$ .001 ; lean men baseline, $M=22.87, S D=13.0$; first session, $M=29.53, S D=16.2, p=.013$; men with obesity baseline, $M$ $=32.33, S D=19.5$; first session $M=33.22, S D=17.5, p=$ .739). In a second step, differences in HF power n.u. increase between groups were analyzed. The analysis showed a main effect of $\operatorname{sex}\left[F(1,107)=14.059, p<.001, \eta_{\mathrm{p}}{ }^{2}=.116\right]$ and a Sex $\times$ Weight interaction $\left[F(1,107)=8.926, p=.003, \eta_{\mathrm{p}}{ }^{2}=\right.$ .077], indicating a stronger increase in HF power n.u. in women with obesity $(M=18.40, S D=13.9)$ than in men with obesity $(M=0.89, S D=10.8, p<.001)$, as well as in lean women $(M=8.75, S D=15.5, p=.008$; Fig. 3$)$. The inclusion of the covariates social insecurity, negative body image, and perceived overload in separate analyses did not change the significance of the main effects nor of the interactions.

Social exclusion: Changes from the first to the second session The analysis of changes from the first to the second session showed for mean HR a significant Time $\times$ Weight interaction $\left[F(1,103)=11.701, p=.001, \eta_{\mathrm{p}}{ }^{2}=.102\right]$. Lean participants had a general decrease in mean HR, independent of condition (1st session, $M=76.93, S D=10.5 ; 2$ nd session, $M=76.02, S D=10.1, p=.014)$, and participants with obesity showed an increase in mean HR (1st session, $M=76.86, S D=$ 8.4 ; 2 nd session, $M=77.71, S D=8.8, p=.021)$.
The analysis of $H F$ power n.u. showed a main effect of time $\left[F(1,103)=15.963, p<.001, \eta_{\mathrm{p}}{ }^{2}=.134\right]$ and an interaction of Time $\times$ Condition $\times$ Sex $\times$ Weight $[F(1$, $\left.103)=5.306, p=.023, \eta_{\mathrm{p}}{ }^{2}=.049\right]$. Women with obesity that were excluded in the second session exhibited a significantly higher response $(M=55.1, S D=14.3)$ than did excluded men with obesity $(M=29.8, S D=17.3, p<$ $.001)$, excluded lean women $(M=41.9, S D=22.3, p=$ $.040)$, included women with obesity $(M=37.3, S D=16.5$, $p=.006)$, and included lean women $(M=41.8, S D=18.7, p$ $=.040)$. In the inclusion condition, all groups but lean women showed a decrease of HF power n.u. over time (lean women 1 st session, $M=40.4, S D=20.1$; 2 nd session, $M$ $=41.8, S D=18.7, p=.601$; women with obesity 1 st session, $M=44.8, S D=19.6 ; 2$ nd session, $M=37.3, S D=16.5$, $p=.008$; lean men 1st session, $M=34.8, S D=19.6 ; 2$ nd session, $M=25.0, S D=13.2, p=.001$; men with obesity $1 \mathrm{st}$ session, $M=34.5, S D=15.4$; 2 nd session, $M=29.4, S D=$ $18.4, p=.089$ ). The inclusion of the covariates social insecurity, negative body image, and perceived overload in separate analyses did not change the significance of the main effects nor of the interactions.

\section{Phasic heart period changes from the first to the second Cyberball session: Social inclusion versus social exclusion}

The analysis of the event-related changes between consecutive IBIs in the first and second sessions showed significant main effects of IBI $[F(3,309)=10.030, \varepsilon=.857, p<.001$, $\left.\eta_{\mathrm{p}}{ }^{2}=.089\right]$ and condition $\left[F(1,103)=8.079, p=.005, \eta_{\mathrm{p}}{ }^{2}=\right.$ .073 ] , as well as a Time $\times$ IBI $\times$ Condition $\times$ Weight interaction $\left[F(3,309)=2.959, p=.033, \eta_{\mathrm{p}}{ }^{2}=.028\right]$. In the second session of the experiment, post-hoc tests revealed that participants with obesity exhibited stronger cardiac slowing in IBI0 and IBI+1 in the inclusion condition (IBI0, $M=9.28$, $S D=10.9$; IBI+1, $M=6.91, S D=9.6$ ) than did participants with obesity in the exclusion condition (IBI0, $M=4.14, S D$ $=5.0, p=.040$; IBI $+1, M=2.06, S D=4.1, p=.082$ ). Lean participants exhibited stronger cardiac slowing in IBI+1 and IBI+2 in the inclusion condition (IBI+1, $M=8.36, S D=$ 13.8; IBI+2, $M=6.07, S D=12.6$ ) than did the lean participants in the exclusion condition (IBI+1, $M=0.79, S D=$ $10.9, p=.007$; IBI $+2, M=0.02, S D=4.3, p=.027$ ). Additionally, all groups but excluded individuals with obesity showed a significant increase in heart period length from IBI-1 to IBI0 in the second part of the experiment (lean individuals inclusion IBI- $1, M=3.39, S D=10.9$; IBI0, $M=$ 8.22, $S D=14.6, p=.013$; lean individuals exclusion IBI-1, $M=0.68, S D=14.1$; IBI0, $M=4.97, S D=7.9, p=.032$; individuals with obesity inclusion IBI- $1, M=2.58, S D=8.5$; IBI0, $M=9.28, S D=11.5, p=.001$; individuals with obesity exclusion IBI-1, $M=2.21, S D=4.9$; IBI0, $M=4.14, S D=$ 5.0, $p=.322$; Fig. 4). 

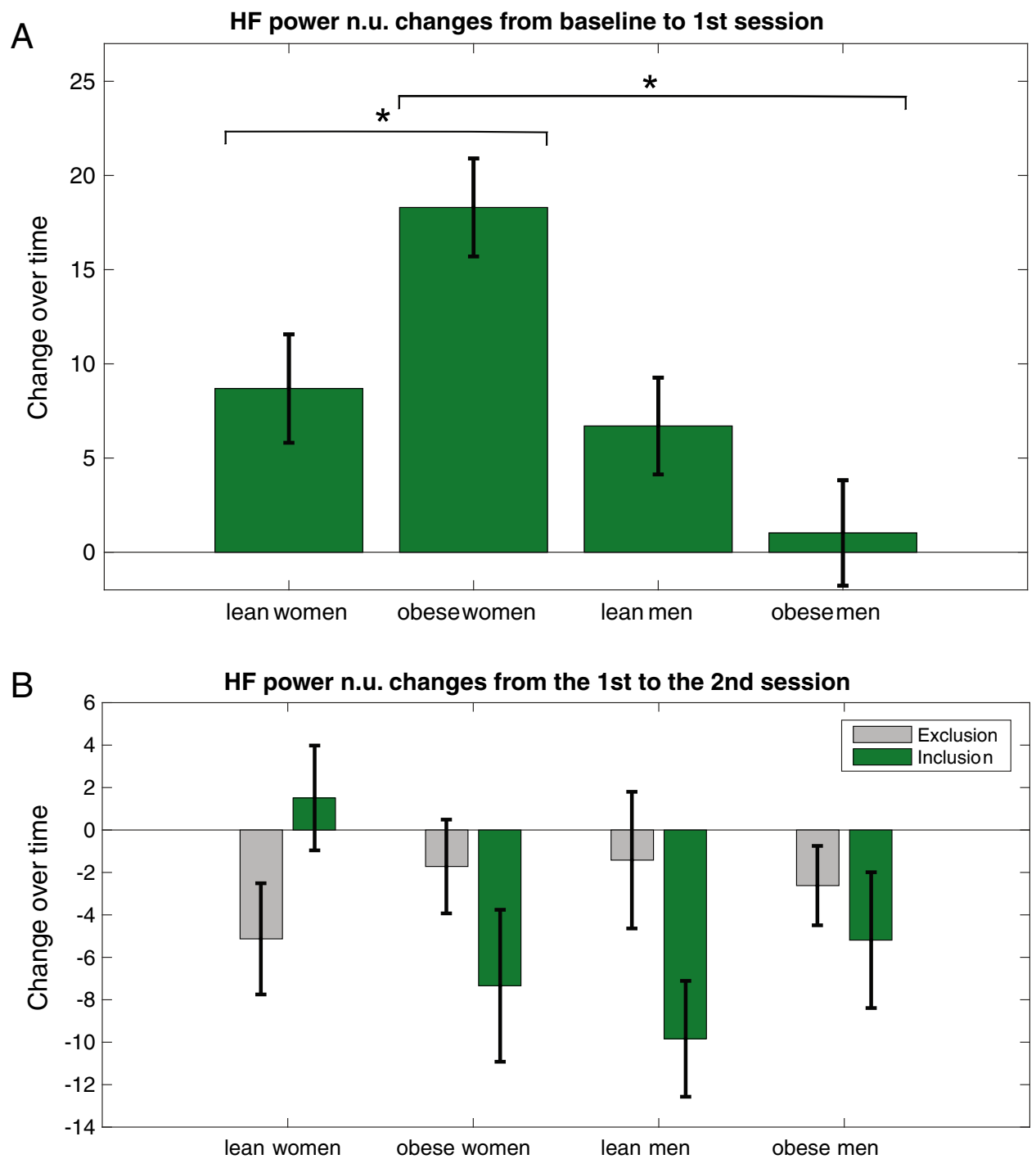

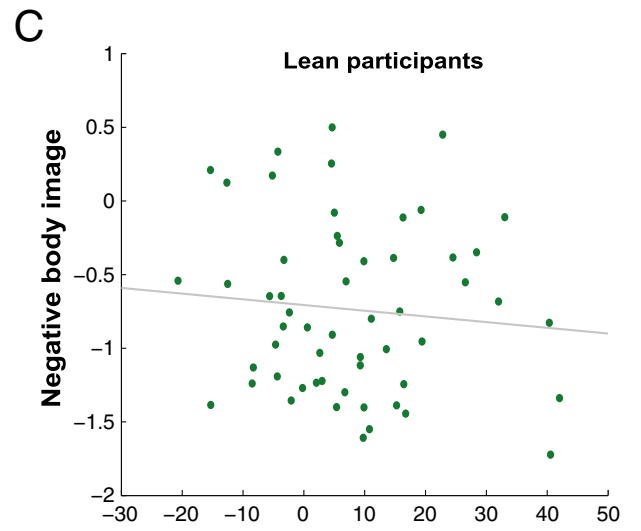

HF power n.u. changes from baseline to session 1

Fig. 3 Parasympathetic activity. Values represent means $\pm S E$ s. (A) Changes in HF power normalized units (n.u.) from baseline to the first experimental session show a significantly stronger increase in women with obesity when confronted with a social interaction [Sex $\times$ Weight interaction, $\left.F(4,107)=8.926, p=.003, \eta_{\mathrm{p}}{ }^{2}=.077\right]$. (B) Changes in HF power n.u. from the first to the second experimental session, showing that

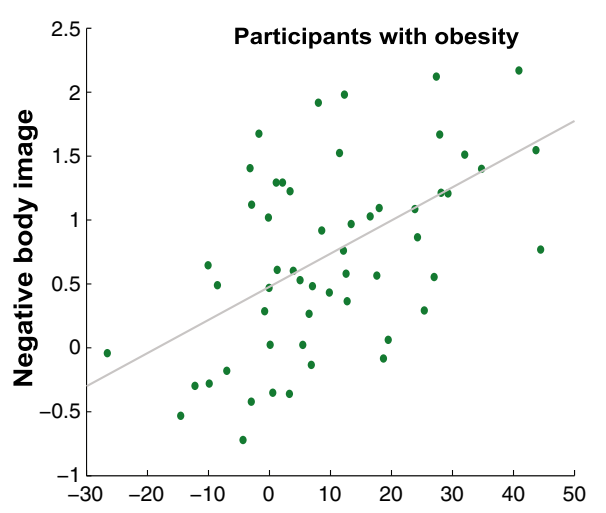

HF power n.u. changes from baseline to session 1

all groups but lean women showed a decrease in HF power n.u. over time in the inclusion condition [Time $\times$ Condition $\times$ Sex $\times$ Group interaction, $F(1,103)=5.306, p=.023, \eta_{\mathrm{p}}{ }^{2}=.049 \mathrm{]}$. (C) In participants with obesity, changes in HF power n.u. were correlated with negative body image $(r=$ $.52, n=56, p<.01)$ 


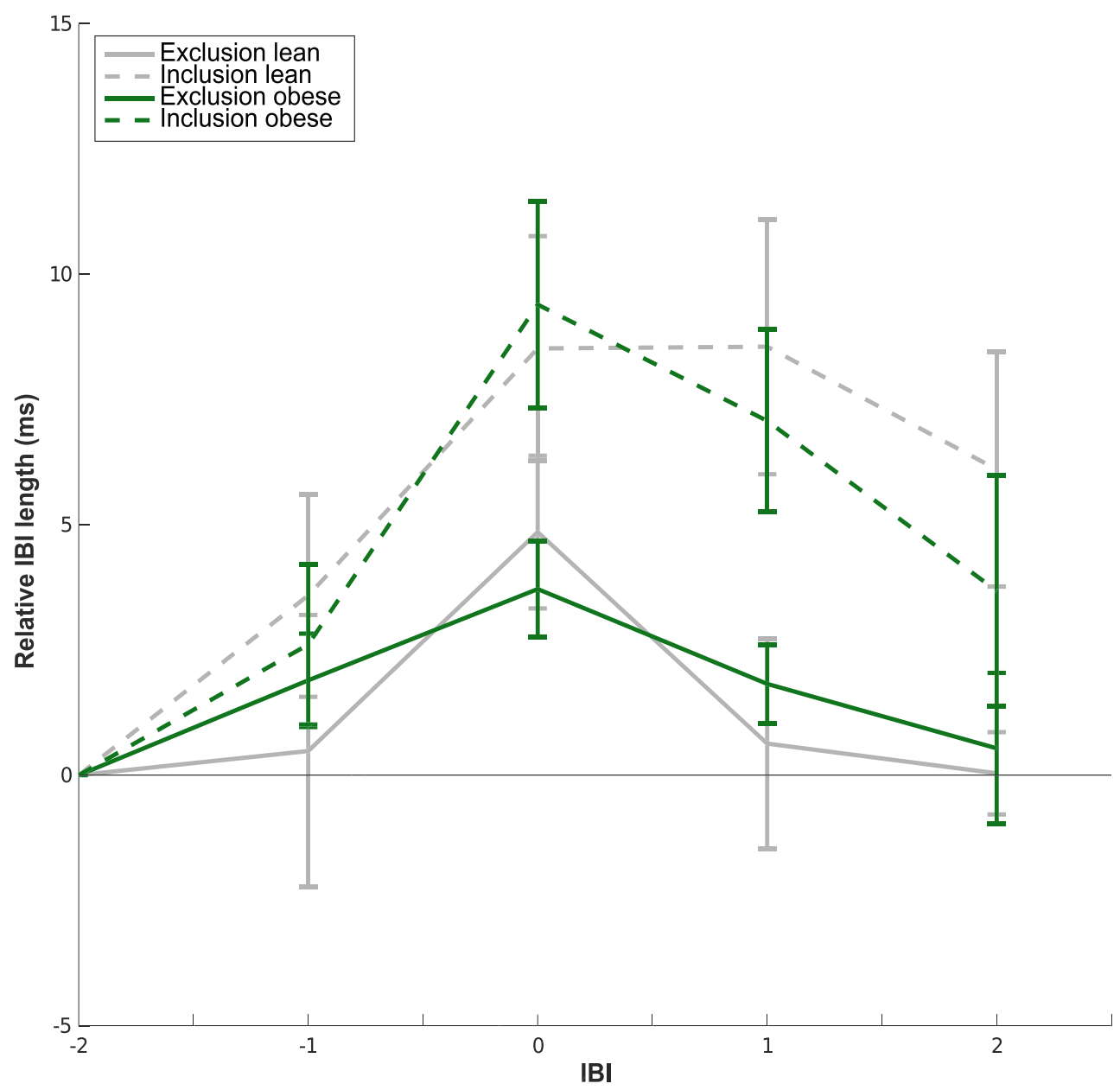

Fig. 4 Phasic heart period changes. Values represent means $\pm S E$ s. Participants with obesity exhibited significantly stronger cardiac slowing in IBI0 in the inclusion than in the exclusion condition.

\section{Trait influences on affective response and parasympathetic activity}

To examine the possible influence of trait variables on affective responses during social interaction, correlation coefficients were calculated for the changes in mood, happiness, and the feeling of being accepted from baseline to the last session, as well as for social insecurity, negative body image, and perceived overload. In the lean group, happiness after exclusion was negatively correlated with social insecurity $[r(27)=-.41, p=.032]$. In the excluded group with obesity, negative correlations between mood and social insecurity $[r(28)=-.48, p=.009]$ and happiness and negative body image $[r(28)=-.38, p=.048]$ were found. In the included group with obesity, mood was negatively correlated with social insecurity $[r(28)=-.43, p=.022]$.

To assess the influences of trait variables on parasympathetic activity during social interaction, correlation coefficients were calculated for HF power n.u., social insecurity, negative body image, and perceived overload. The analysis
Furthermore, excluded individuals with obesity are the only group without a significant increase from IBI- 1 to IBI0 [Time $\times$ IBI $\times$ Condition $\times$ Group interaction, $\left.F(3,309)=2.959, p=.033, \eta_{\mathrm{p}}{ }^{2}=.028\right]$

of the changes from baseline to the first session showed in the lean group no significant correlations between HRV parameters, state, and trait characteristics. In the group with obesity, however, a significant positive correlation was found between the changes in HF power n.u. and negative body image $[r(56)=.52, p<.001$; Fig. 3$]$. The correlation coefficients of the association of HF power n.u. changes and negative body image were significantly different between the lean group and the group with obesity (Fisher's $r$-to-z transformation, $z=-3.45, p<.001$ ).

The analysis of the changes from the first to the second session showed in the excluded lean group, the included lean group, and the excluded group with obesity no significant correlations between HRV parameters and state and trait characteristics. The analysis of the included group with obesity revealed a significant positive correlation between the changes of HF power n.u. and negative body image $[r(28)=$ $.46, p=.015]$.

We found no associations between the trait variables and phasic heart period changes. 


\section{Influence of affective responses on parasympathetic activity}

To assess the influences of the affect variables on parasympathetic activity during social interaction, correlation coefficients were calculated for HF power n.u. and changes in mood, happiness, and the feeling of being accepted. The analysis of the changes from baseline to the first session in the lean group showed no significant correlations between changes in HF power n.u. and changes in affective responses. In the group with obesity, however, a negative correlation was found between the changes of HF power n.u. and changes in happiness $[r(56)=-.26, p=.049]$.

The analysis of the changes from the first to the second session showed no significant correlations between the HRV parameters and affect in the excluded lean as well as in the included and excluded groups with obesity. In the included lean group, we found a significant positive correlation between changes of HF power n.u. and changes in the feeling of being accepted $[r(29)=.42, p=.022]$.

There were no associations between affective responses and phasic heart period changes.

\section{Discussion}

Using the Cyberball paradigm, we investigated differences in affective and cardiac responses to social inclusion and exclusion in individuals with and without obesity. We hypothesized that individuals with obesity would exhibit stronger parasympathetic activation than lean individuals when engaging in a novel, potentially stigmatizing social situation, in which they are included and their weight status is visible.

In our study, all participants but men with obesity showed an increase in parasympathetic activity when engaged in an inclusive social situation relative to a resting baseline. This increase was significantly more pronounced in women with obesity. Other studies found heightened parasympathetic activity to be associated with attention to negatively valenced stimuli, such as threatening animals (Jönsson \& HanssonSandsten, 2008) or angry facial expressions (Jönsson \& Sonnby-Borgström, 2003), as well as during the reception of negative as compared to positive social feedback (Vanderhasselt, Remue, Ng, Mueller, \& De Raedt, 2015). In a mother-infant interaction study, mothers exhibited increased parasympathetic activity when their infants displayed distress (Oppenheimer, Measelle, Laurent, \& Ablow, 2013). Interestingly, as the infant's distress increased, the mother's PNS activity decreased over the course of the experiment. Since the mothers were instructed not to respond, the results were interpreted as a regulatory process followed by a response mobilization. Likewise, watching other people suffer evokes an increase in PNS activity (Stellar, Cohen, Oveis, \& Keltner, 2015).

Butler, Wilhelm, and Gross (2006) provided further support for the role of parasympathetic responses during emotion regulation. In their study, participants reappraising or suppressing their emotional response to a short negative film showed higher PNS activity than passively viewing participants. It can be assumed that effortful regulation of emotions requires heightened levels of attention - to internal and external stimuli. The neurovisceral integration model proposes that increased parasympathetic activity together with increased attention improves the individual's capacity to make effective and rapid responses (Thayer \& Lane, 2000, 2009).

According to the aforementioned research, the strong increase in PNS activity from baseline to the first session in women with obesity and with a visible weight status in our study might indicate higher attention to or engagement with the novel and potentially stigmatizing social interaction. A study by Hartung and Renner (2013) found that participants (mainly women) with higher BMI perceive themselves as less socially included and are more sensitive to their actual social inclusion or exclusion status than participants with lower BMI. In a similar vein, women with obesity that were visible during an interaction with another participant, as compared to women with obesity that were invisible, engaged in more friendly behavior during the social interaction. This has been interpreted as a compensatory mechanism in anticipation of prejudice (Miller et al., 1995).

Interpreting increased PNS activity as heightened attention to a novel social situation in women with obesity can be linked to broader theoretical formulations: Pickett and Gardner (2005) proposed an inherent social monitoring system that regulates the level of sensitivity to social information. This monitoring system is adaptive and can be affected by social context or environment. Since humans are dependent on social affiliations, it might have evolved to detect potential threats to belongingness. Consequently, individuals that have a higher need to belong are assumed to show enhanced sensitivity to social cues in order to affiliate and reconnect.

Although we did not find a direct relationship between previous negative social experiences and PNS reactivity in individuals with obesity, we observed an association between negative body image and the changes of parasympathetic activity from baseline to the first session of the Cyberball game in individuals with obesity but not in lean individuals. Importantly, in individuals with obesity but not in lean individuals, negative body image was also highly correlated with social insecurity. Repeated negative social experiences might accumulate over time and result in negative psychological outcomes, such as higher body dissatisfaction (Schwartz \& Brownell, 2004; Stunkard \& Mendelson, 1967). This effect is more pronounced in individuals who report frequent weight-related teasing and stigmatization (Eisenberg, 
Neumark-Sztainer, \& Story, 2003; Friedman et al., 2005; Myers \& Rosen, 1999). In our sample, women with obesity had the highest negative body image, relative to the other groups. During the experimental session, the participant's weight status was continuously visible, which could have provoked higher attention in individuals with obesity and a more negative body image. In line with this interpretation, it has been shown that women with a negative body image perceived social feedback regarding their own body portrait as more negative in comparison with another woman's body portrait, even though the feedback was equal (Alleva, Lange, Jansen, \& Martijn, 2014). Furthermore, women with higher BMI and a visible weight status showed greater rejection expectations by a potential dating partner than did women with higher BMI and an invisible weight status (Blodorn, Major, Hunger, \& Miller, 2016). Kaiser and colleagues (2006) showed that individuals high in prejudice expectation are more vigilant for subliminal prejudice-related cues. The expectation of being a target of appearance-related prejudice might therefore enhance attention in social interactions. Additionally, the group with obesity also showed a relationship between affective responses and HRV that might further support our interpretation of prejudice expectation: Changes of parasympathetic activity from baseline to the first session were negatively related to changes in happiness. Studies on inter-ethnic interactions showed that the expectation of being the target of prejudice increased negative affect in ethnic minorities (Shelton, 2005).

Further, we hypothesized that during social exclusion individuals with obesity would show parasympathetic withdrawal and that this might be influenced by previous weight-related negative social experience and body dissatisfaction. In this study, we could not confirm this hypothesis. In the exclusion session, only lean women showed a significant reduction of PNS activity relative to the first (inclusion) session. Nevertheless, excluded women with obesity still had the highest parasympathetic activity, as compared to the other excluded groups. On the basis of the literature mentioned above, this may indicate higher attentional engagement or stronger emotion regulation in women with obesity than in the other groups (Butler et al., 2006; Jönsson \& HanssonSandsten, 2008; Jönsson \& Sonnby-Borgström, 2003; Oppenheimer et al., 2013; Vanderhasselt et al., 2015).

In addition to tonic parasympathetic activity, we looked at phasic cardiac responses by analyzing the participants' heartbeats around the confederates' ball tosses. Stronger stimulusrelated cardiac slowing indicates higher PNS activity (Gunther Moor et al., 2010). We found that individuals with obesity who were included in the game showed significantly stronger cardiac slowing around the ball throws than did individuals with obesity who were excluded. We found the same (but not significant) pattern in lean individuals. There is substantial evidence that phasic cardiac slowing is more pronounced for motivationally relevant stimuli (Somsen et al., 2000; van der Veen et al., 2004). Jennings and van der Molen (2002) summarized in their review that at the peak of cardiac slowing, anticipatory attention, motor readiness, cognitive load, and energy accumulation are maximized. Balconi, Brambilla, and Falbo (2009) showed increased cardiac deceleration to highly arousing relative to low-arousing stimuli. Higher responses in the inclusion than in the exclusion condition in our study might therefore indicate a higher attentional engagement in this social interaction game.

We found no significant differences in heart period responses between individuals with obesity and lean individuals in the exclusion condition. However, excluded individuals with obesity were the only group without a typical significant increase in heart period length during stimulus occurrence. Previously, we argued (Kube, Schrimpf, et al., 2016) that individuals with obesity might apply coping mechanisms such as psychological disengagement (Crocker \& Major, 1989) or avoidance (Puhl \& Brownell, 2003) to prevent the detrimental effects of negative social feedback. In line with this, it has been shown that individuals with a history of victimization exhibited blunted skin conductance (Iffland, Sansen, Catani, $\&$ Neuner, 2014b) and cardiovascular responses to social exclusion (Newman, 2014). These studies provide evidence that frequent negative social feedback could result in reduced physiological responses to social exclusion, which might be an adaptive strategy that is complementary to psychological disengagement.

Physiologically, more phasic cardiac deceleration should be associated with higher tonic HRV. In our analysis of phasic heart period changes, we did not include all events but only ball tosses between the computer-generated players to avoid interferences with motor preparation or key presses. Phasic heart period changes on this subset of events were not associated with tonic PNS activity. To our knowledge, only one previous study combined the analysis of HRV over a certain time period and phasic heart rate changes during stimulus occurrence (Abercrombie, Chambers, Greischar, \& Monticelli, 2008). In their study, they found a relationship between tonic autonomic arousal (elevated mean HR, interpreted as parasympathetic withdrawal) and stronger heart rate deceleration in response to emotional pictures (a marker of parasympathetic activity), which was interpreted as an increased attentional processing. A greater tonic PNS withdrawal was explained as a preparation of the attentional system, which might foster stronger HR deceleration during stimulus onset. However, independent of a relationship between variables, we found higher tonic and phasic PNS activity in inclusionary situations, which might deviate from Abercrombie and colleague's findings.

Finally, we hypothesized that individuals with obesity are morenegativelyaffected by socialexclusion thanleanindividuals. We measured mood, happiness, and the feeling of being 
accepted prior, between, and after the two sessions. In our study, all participants felt worse, less accepted, and were less happy afteran episode of socialexclusion than afteran episode of social inclusion. These findings are in line with previous studies using the Cyberball or other social exclusion paradigms (see Blackhart et al., 2009; Gerber \& Wheeler, 2009). Inaddition, we found that women with obesity show on the one hand the greatest decrease in mood after exclusion but on the other hand also the greatest increase in mood after inclusion, whichpartiallyconfirmsourhypothesis. Forhappinessand the feeling of being accepted, women with obesity and lean men both exhibit a reduction after an episode of exclusion versus after an episode of inclusion. Furthermore, socially excluded women with obesity felt less accepted than socially excluded lean women. Interestingly, decreasesinmoodandhappinessin individuals with obesity after exclusion were boosted by a more negative body image and higher social insecurity.

Only few studies examined negative affect after social exclusion or rejection in individuals with obesity. Crocker, Cornwell, and Major (1993) found that women with overweight attribute ambiguous negative social feedback to their weight and show a more negative affect than do lean women. Moreover, the more women with overweight attributed the negative social feedback to their weight, the higher was their negative affect. Although this study did not directly measure the influence of negative body image, the association between weight attribution and negative affect might be influenced by negative body image. Taken together, these results suggest that body image or social insecurity might enhance negative emotions after negative social feedback in individuals with overweight or obesity.

Moreover, not only women with obesity but also lean men showed a stronger negative affect after social exclusion. It is not clear why this effect was absent in men with obesity. Previous research reported divergent results concerning sex differences in emotional processing and response to social exclusion or rejection. For example, sex differences have been found in neural correlates of emotional processing (Whittle, Yücel, Yap, \& Allen, 2011; but cf. García-García et al., 2016, for a meta-analysis of visual emotional stimuli). Women tend to report stronger positive and negative emotion intensity than men (Fujita, Diener, \& Sandvik, 1991). With regard to social exclusion experiences, women have been found to report stronger distress after negative social interactions than men (Birditt \& Fingerman, 2003). In another study, women exhibited a stronger increase in cortisol level after social rejection than men, but did not differ in selfreported negative affect (Stroud, Salovey, \& Epel, 2002). A lack of sex differences in negative affect after social rejection has also been found by other studies (Blackhart, Eckel, \& Tice, 2007; Seidel et al., 2013; Stillman et al., 2009). With respect to weight, obesity status has been related to poorer psychosocial outcomes in females but not in males (Barry,
Pietrzak, \& Petry, 2008; Merten, Wickrama, \& Williams, 2008), whereas other studies did not find a sex difference in the relation between obesity and psychological distress (Friedman, Reichmann, Costanzo, \& Musante, 2002). Emotional responses to weight-related stigmatization have been found to differ between sexes, showing that stigmatization is not predicting negative affect in males but in females (Puhl \& Luedicke, 2012). Other studies did not find sex differences (Almenara \& Ježek, 2015; Friedman et al., 2005). Mixed findings on sex and obesity differences in affective response to social exclusion indicate the need for further work on the interaction of sex and weight status in the context of negative social experiences.

In this study, baseline HF-HRV significantly differed between men and women, which is in line with a current metaanalysis on sex differences in autonomic cardiac control (Koenig \& Thayer, 2016), reporting greater dominance of parasympathetic activity in females than in males. Interestingly, we did not find any significant baseline differences in HF-HRV between participants with and without obesity. This deviates from other studies that have reported reduced parasympathetic resting-state activity in individuals with obesity relative to normal-weight individuals (e.g., Birch, Duncan, \& Franklin, 2012; Monda et al., 2006; RodríguezColón, Bixler, Li, Vgontzas, \& Liao, 2010; Tonhajzerova et al., 2008). However, these studies did not control for potential influencing metabolic or cardiovascular alterations to the extent that we did. Participants with pre-existing alterations were not included in our study. Metabolic factors independent of BMI (Poliakova et al., 2012) as well as insulin resistance and inflammation dependent of visceral fat mass (Kaufman, Kaiser, Steinberger, Kelly, \& Dengel, 2007) have been shown to influence HRV. In addition, we included participants with and without obesity that reported a comparable hours of sports per week. Nagai and Moritani (2004) found that physical activity is positively associated with resting-state PNS activity in lean children as well as in children with obesity. It is thus conceivable that the absence of group differences in baseline HF-HRV in our study is due to these inclusion and matching criteria.

The present study has several limitations. We did not account for the potential influence of respiration rate on HFHRV. In some studies, respiration rate has been found to be a confounder in HF-HRV data (Grossman \& Taylor, 2007; Penttilä et al., 2001). However, the analysis of HF-HRV uncorrected for respiration rate is sufficient for tasks with comparable demands and spontaneous breathing (Denver, Reed, \& Porges, 2007; Grossman \& Taylor, 2007). Nevertheless, a potential influence of different respiration rates between groups on the results of HRV cannot be fully excluded in this study. Furthermore, we cannot completely rule out the possibility of obesity-related cardiovascular or respiratory alterations. In other studies, no differences in respiration rate have 
been found between children with and without obesity (Tonhajzerova et al., 2008) and between adults with overweight, obesity, and morbid obesity (Laederach-Hofmann, Mussgay, \& Ruddel, 2000). However, a direct comparison of lean individuals and individuals with severe and morbid obesity indicated a higher respiratory rate in individuals with obesity (Chlif, Keochkerian, Choquet, Vaidie, \& Ahmaidi, 2009). In this study, we did not expect higher or lower breathing frequencies between participants and tasks as participants were instructed to sit calmly and not to speak during ECG measurements. All participants reported no diagnosed respiratory or cardiovascular diseases.

Furthermore, the present task design is not able to disentangle emotion regulation from attentional processes. Both are associated with an increase in parasympathetic activity (Butler et al., 2006; Jönsson \& Hansson-Sandsten, 2008; Jönsson \& Sonnby-Borgström, 2003; Oppenheimer et al., 2013; Stellar et al., 2015; Vanderhasselt et al., 2015). Conversely, other studies did not find a relationship between heightened parasympathetic activity and attention or emotion regulation (e.g., Demaree et al., 2006; Frazier, Strauss, \& Steinhauer, 2004; Palomba, Sarlo, Angrilli, Mini, \& Stegagno, 2000). However, it has been shown that attention and emotion regulation share common neuronal networks (Pessoa, 2008). Moreover, Todd, Cunningham, Anderson, and Thompson (2012) proposed that an individual's affective memory acquired during past experiences habitually biases attention to salient environmental stimuli. Thus, such biased attention might represent a form of emotion regulation. We therefore assume that the specific group differences in HRV found in this study can be interpreted as emotionally biased attention. Additional eye tracking and analysis of eye movement/fixation and pupil dilation data could support this interpretation.

Although trait stress level (perceived overload) did not influence HRV results in this study, we cannot rule out a potential influence of a group difference in stress regulation on HRV. Future studies on social exclusion or social rejection could explicitly assess stress regulation abilities.

Finally, the Cyberball paradigm is a laboratory instrument with little contextual information in which the group interaction is restricted to tossing a ball. Although the paradigm is widely established, it lacks the generalizability to and the reflection of real-life interactions, which are by nature more significant and more complex. Inferences from behavioral and psychophysiological results obtained with the Cyberball paradigm in the lab to real-life interactions must be carefully considered and ideally complemented with more realistic social interaction scenarios.

The results of this study have implications for future studies. Subjective measures such as body image and previous social experiences should be taken into consideration in future studies on obesity. The association between negative body image and heightened parasympathetic activity during social interactions in individuals with obesity indicate that negative body image might have an influence on social functioning. Behavioral interventions for individuals with obesity with a special focus on body image and social insecurity might therefore be promising for an improvement in wellbeing. In summary, the present findings add to our understanding of how individuals with obesity process social interactions. We show that women with obesity exhibit higher parasympathetic activity during social interactions, which might indicate a higher vigilance in order to quickly detect signs of prejudice and apply adaptive psychophysiological strategies. This might be especially true for individuals with obesity and with a more negative body image.

Author note We thank all of the study participants for their cooperation. We also thank R. Jost, J. Tippmann, M. Vollmann, C. Wickner, and M. Ziermann for their help with recruiting participants and data collection. For general assistance during the study, we thank B. Johst and R. Menger. We especially thank S. Heba for providing MATLAB-based scripts for analysis of the HR data. This work was supported by the Max Planck International Research Network on Aging (MaxNetAging) (to A.S.), the German Federal Ministry of Education and Research (FKZ: 01EO1001; to J.K., J.N., A.H., and A.V.), and the German Research Foundation (SFB 1052 Obesity Mechanisms; to J.N., A.H., and A.V.). The authors declare that they have no conflicts of interest.

\section{References}

Abercrombie, H. C., Chambers, A. S., Greischar, L., \& Monticelli, R. M. (2008). Orienting, emotion, and memory: Phasic and tonic variation in heart rate predicts memory for emotional pictures in men. Neurobiology of Learning and Memory, 90, 644-650. doi:10.1016 /j.nlm.2008.08.001

Alleva, J. M., Lange, W.-G., Jansen, A., \& Martijn, C. (2014). Seeing ghosts: Negative body evaluation predicts overestimation of negative social feedback. Body Image, 11, 228-232. doi:10.1016/j. bodyim.2014.03.001

Almenara, C. A., \& Ježek, S. (2015). The source and impact of appearance teasing: An examination by sex and weight status among early adolescents from the Czech Republic. Journal of School Health, 85, 163-170. doi:10.1111/josh.12236

Alvares, G. A., Quintana, D. S., Kemp, A. H., Van Zwieten, A., Balleine, B. W., Hickie, I. B., \& Guastella, A. J. (2013). Reduced heart rate variability in social anxiety disorder: Associations with gender and symptom severity. PLOS ONE, 8, e70468. doi:10.1371/journal. pone.0070468

Andreyeva, T., Puhl, R. M., \& Brownell, K. D. (2008). Changes in perceived weight discrimination among Americans, 1995-1996 through 2004-2006. Obesity, 16, 1129-1134. doi:10.1038 /oby.2008.35

Balconi, M., Brambilla, E., \& Falbo, L. (2009). Appetitive vs. defensive responses to emotional cues. Autonomic measures and brain oscillation modulation. Brain Research, 1296, 72-84. doi:10.1016/j. brainres.2009.08.056

Barreto, M., \& Ellemers, N. (2015). Detecting and experiencing prejudice: New answers to old questions. Advances in Experimental Social Psychology, 52, 139-219. doi:10.1016/bs.aesp.2015.02.001

Barry, D., Pietrzak, R. H., \& Petry, N. M. (2008). Gender differences in associations between body mass index and DSM-IV mood and anxiety disorders: Results from the National Epidemiologic Survey on 
alcohol and related conditions. Annals of Epidemiology, 18, 458466. doi:10.1016/j.annepidem.2007.12.009

Baumeister, R. F., \& Leary, M. R. (1995). The need to belong: Desire for interpersonal attachments as a fundamental human motivation. Psychological Bulletin, 117, 497-529. doi:10.1037/00332909.117.3.497

Beck, A. T., Steer, R. A., \& Carbin, M. G. (1988). Psychometric properties of the Beck Depression Inventory: Twenty-five years of evaluation. Clinical Psychology Review, 8, 77-100. doi:10.1016/02727358(88)90050-5

Billman, G. (2013). The LF/HF ratio does not accurately measure cardiac sympatho-vagal balance. Frontiers in Physiology, 4, 26. doi:10.3389/fphys.2013.00026

Birch, S. L., Duncan, M. J., \& Franklin, C. (2012). Overweight and reduced heart rate variability in British children: An exploratory study. Preventive Medicine, 55, 430-432. doi:10.1016/j. ypmed.2012.09.015

Birditt, K. S., \& Fingerman, K. L. (2003). Age and gender differences in adults' descriptions of emotional reactions to interpersonal problems. Journals of Gerontology, 58B, P237-P245. doi:10.1093 /geronb/58.4.P237

Blackhart, G. C., Eckel, L. A., \& Tice, D. M. (2007). Salivary cortisol in response to acute social rejection and acceptance by peers. Biological Psychology, 75, 267-276. doi:10.1016/j. biopsycho.2007.03.005

Blackhart, G. C., Nelson, B. C., Knowles, M. L., \& Baumeister, R. F. (2009). Rejection elicits emotional reactions but neither causes immediate distress nor lowers self-esteem: A meta-analytic review of 192 studies on social exclusion. Personality and Social Psychology Review, 13, 269-309. doi:10.1177/1088868309346065

Blodorn, A., Major, B., Hunger, J., \& Miller, C. (2016). Unpacking the psychological weight of weight stigma: A rejection-expectation pathway. Journal of Experimental Social Psychology, 63, 69-76. doi:10.1016/j.jesp.2015.12.003

Borkenau, P., \& Ostendorf, F. (1993). NEO-FFI: NEO-Fünf-Faktoren Inventar nach Costa und McCrae. Göttingen, Germany: Hogrefe.

Botvinick, M. M., Cohen, J. D., \& Carter, C. S. (2004). Conflict monitoring and anterior cingulate cortex: An update. Trends in Cognitive Sciences, 8, 539-546. doi:10.1016/j.tics.2004.10.003

Burr, R. L. (2007). Interpretation of normalized spectral heart rate variability indices in sleep research: A critical review. Sleep, 30, 913919.

Butler, E. A., Wilhelm, F. H., \& Gross, J. J. (2006). Respiratory sinus arrhythmia, emotion, and emotion regulation during social interaction. Psychophysiology, 43, 612-622. doi:10.1111/j.14698986.2006.00467.x

Carpenter, K. M., Hasin, D. S., Allison, D. B., \& Faith, M. S. (2000). Relationships between obesity and DSM-IV major depressive disorder, suicide ideation, and suicide attempts: Results from a general population study. American Journal of Public Health, 90, 251-257. doi:10.2105/AJPH.90.2.251

Chlif, M., Keochkerian, D., Choquet, D., Vaidie, A., \& Ahmaidi, S. (2009). Effects of obesity on breathing pattern, ventilatory neural drive and mechanics. Respiratory Physiology and Neurobiology, 168, 198-202. doi:10.1016/j.resp.2009.06.012

Cohen, S., Kamarck, T., \& Mermelstein, R. (1983). A global measure of perceived stress. Journal of Health and Social Behavior, 24, 385396. doi:10.2307/2136404

Conradt, M., Dierk, J. M., Schlumberger, P., Rauh, E., Hebebrand, J., \& Rief, W. (2008). Who copes well? Obesity-related coping and its associations with shame, guilt, and weight loss. Journal of Clinical Psychology, 64, 1129-1144. doi:10.1002/jclp.20501

Cooper, P. J., Taylor, M. J., Cooper, Z., \& Fairbum, C. G. (1987). The development and validation of the body shape questionnaire. International Journal of Eating Disorders, 6, 485-494. doi:10.1002 /1098-108X(198707)6:4<485::AID-EAT2260060405>3.0.CO;2-O
Crandall, C. S. (1994). Prejudice against fat people: Ideology and selfinterest. Journal of Personality and Social Psychology, 66, 882894. doi:10.1037/0022-3514.66.5.882

Crocker, J., Cornwell, B., \& Major, B. (1993). The stigma of overweight: Affective consequences of attributional ambiguity. Journal of Personality and Social Psychology, 64, 60-70. doi:10.1037/00223514.64.1.60

Crocker, J., \& Major, B. (1989). Social stigma and self-esteem: The selfprotective properties of stigma. Psychological Review, 96, 608-630. doi:10.1037/0033-295X.96.4.608

DeJong, W. (1980). The stigma of obesity: The consequences of naive assumptions concerning the causes of physical deviance. Journal of Health and Social Behavior, 21, 75-87. doi:10.2307/2136696

Demaree, H. A., Schmeichel, B. J., Robinson, J. L., Pu, J., Everhart, D. E., \& Berntson, G. G. (2006). Up- and down-regulating facial disgust: Affective, vagal, sympathetic, and respiratory consequences. Biological Psychology, 71, 90-99. doi:10.1016/j. biopsycho.2005.02.006

Denver, J. W., Reed, S. F., \& Porges, S. W. (2007). Methodological issues in the quantification of respiratory sinus arrhythmia. Biological Psychology, 74, 286-294. doi:10.1016/j.biopsycho.2005.09.005

Eisenberg, M. E., Neumark-Sztainer, D., \& Story, M. (2003). Associations of weight-based teasing and emotional well-being among adolescents. Archives of Pediatrics and Adolescent Medicine, 157, 733-738. doi:10.1016/S1054-139X(02)00610-9

Eisenberger, N. I., Lieberman, M. D., \& Williams, K. D. (2003). Does rejection hurt? An FMRI study of social exclusion. Science, 302, 290-292. doi:10.1126/science.1089134

Fliege, H., Rose, M., Arck, P., Levenstein, S., \& Klapp, B. F. (2001). Validierung des "Perceived Stress Questionnaire" (PSQ) an einer deutschen Stichprobe. Diagnostica, 47, 142-152. doi:10.1026 /0012-1924.47.3.142

Frazier, T. W., Strauss, M. E., \& Steinhauer, S. R. (2004). Respiratory sinus arrhythmia as an index of emotional response in young adults. Psychophysiology, 41, 75-83. doi:10.1046/j.14698986.2003.00131.x

Friedman, K. E., Reichmann, S. K., Costanzo, P. R., Zelli, A., Ashmore, J. A., \& Musante, G. J. (2005). Weight stigmatization and ideological beliefs: Relation to psychological functioning in obese adults. Obesity Research, 13, 907-916. doi:10.1038/oby.2005.105

Friedman, K. E., Reichmann, S. K., Costanzo, P. R., \& Musante, G. J. (2002). Body image partially mediates the relationship between obesity and psychological distress. Obesity Research, 10, 33-41. doi:10.1038/oby.2002.5

Fujita, F., Diener, E., \& Sandvik, E. (1991). Gender differences in negative affect and well-being: The case for emotional intensity. Journal of Personality and Social Psychology, 61, 427-434. doi:10.1037 /0022-3514.61.3.427

Gaebler, M., Daniels, J. K., Lamke, J.-P., Fydrich, T., \& Walter, H. (2013). Heart rate variability and its neural correlates during emotional face processing in social anxiety disorder. Biological Psychology, 94, 319-330. doi:10.1016/j.biopsycho.2013.06.009

García-García, I., Kube, J., Gaebler, M., Horstmann, A., Villringer, A., \& Neumann, J. (2016). Neural processing of negative emotional stimuli and the influence of age, sex and task-related characteristics. Neuroscience \& Biobehavioral Reviews, 68, 773-793. doi:10.1016/j. neubiorev.2016.04.020

Garner, D. M. (1991). Eating disorder inventory-2. Odessa, FL: Psychological Assessment Resources.

Gerber, J., \& Wheeler, L. (2009). On being rejected: A meta-analysis of experimental research on rejection. Perspectives on Psychological Science, 4, 468-488. doi:10.1111/j.1745-6924.2009.01158.x

Goffman, E. (1963). Stigma; notes on the management of spoiled identity: A spectrum book. Englewood Cliffs, NJ: Prentice-Hall.

Grossman, P., \& Taylor, E. W. (2007). Toward understanding respiratory sinus arrhythmia: Relations to cardiac vagal tone, 
evolution and biobehavioral functions. Biological Psychology, 74, 263-285. doi:10.1016/j.biopsycho.2005.11.014

Gunther Moor, B., Bos, M. G. N., Crone, E. A., \& van der Molen, M. W. (2014). Peer rejection cues induce cardiac slowing after transition into adolescence. Developmental Psychology, 50, 947-955. doi:10.1037/a0033842

Gunther Moor, B., Crone, E. A., \& van der Molen, M. W. (2010). The heartbrake of social rejection: Heart rate deceleration in response to unexpected peer rejection. Psychological Science, 21, 1326-1333. doi:10.1177/0956797610379236

Hartung, F.-M., \& Renner, B. (2013). Perceived and actual social discrimination: The case of overweight and social inclusion. Frontiers in Psychology, 4, 147. doi:10.3389/fpsyg.2013.00147

Iffland, B., Sansen, L. M., Catani, C., \& Neuner, F. (2014a). Rapid heartbeat, but dry palms: Reactions of heart rate and skin conductance levels to social rejection. Frontiers in Psychology, 5, 956. doi:10.3389/fpsyg.2014.00956

Iffland, B., Sansen, L. M., Catani, C., \& Neuner, F. (2014b). The trauma of peer abuse: Effects of relational peer victimization and social anxiety disorder on physiological and affective reactions to social exclusion. Frontiers in Psychiatry, 5, 26. doi:10.3389/fpsyt.2014.00026

Jennings, J. R., \& van der Molen, M. W. (2002). Cardiac timing and the central regulation of action. Psychological Research, 66, 337-349. doi:10.1007/s00426-002-0106-5

Joanisse, L., \& Synnott, A. (1999). Fighting back: Reactions and resistance to the stigma of obesity. In J. Sobal \& D. Maurer (Eds.), Interpreting weight: The social management of fatness and thinness (pp. 49-70). New York, NY: Aldine de Gruyter.

Jönsson, P., \& Hansson-Sandsten, M. (2008). Respiratory sinus arrhythmia in response to fear-relevant and fear-irrelevant stimuli. Scandinavian Journal of Psychology, 49, 123-131. doi:10.1111 /j.1467-9450.2008.00638.x

Jönsson, P., \& Sonnby-Borgström, M. (2003). The effects of pictures of emotional faces on tonic and phasic autonomic cardiac control in women and men. Biological Psychology, 62, 157-173. doi:10.1016 /S0301-0511(02)00114-X

Kaiser, C. R., Vick, S. B., \& Major, B. (2006). Prejudice expectations moderate preconscious attention to cues that are threatening to social identity. Psychological Science, 17, 332-338. doi:10.1111/j.14679280.2006.01707.x

Kaufman, C. L., Kaiser, D. R., Steinberger, J., Kelly, A. S., \& Dengel, D. R. (2007). Relationships of cardiac autonomic function with metabolic abnormalities in childhood obesity. Obesity, 15, 1164-1171. doi:10.1038/oby.2007.619

Kemper, C. J., Lutz, J., \& Neuser, J. (2012). Konstruktion und Validierung einer Kurzform der Skala Angst vor negativer Bewertung (SANB-5). Klinische Diagnostik und Evaluation, 4, 343-360.

Koenig, J., \& Thayer, J. (2016). Sex differences in healthy human heart rate variability: A meta-analysis. Neuroscience and Biobehavioral Reviews, 64, 288-310. doi:10.1016/j.neubiorev.2016.03.007

Kube, J., Schrimpf, A., Garcia-Garcia, I., Villringer, A., Neumann, J., \& Horstmann, A. (2016). Differential heart rate responses to social and monetary reinforcement in women with obesity. Psychophysiology, 53, 868-879. doi:10.1111/psyp.12624

Kurzban, R., \& Leary, M. R. (2001). Evolutionary origins of stigmatization: The functions of social exclusion. Psychological Bulletin, 127, 187-208. doi:10.1037/0033-2909.127.2.187

Laederach-Hofmann, K., Mussgay, L., \& Ruddel, H. (2000). Autonomic cardiovascular regulation in obesity. Journal of Endocrinology, 164, 59-66. doi:10.1677/joe.0.1640059

Legenbauer, T., Vocks, S., \& Schütt-Strömel, S. (2007). Validierung einer deutschsprachigen Version des Body Image Avoidance Questionnaire BIAQ. Diagnostica, 53, 218-225. doi:10.1026 10012-1924.53.4.218

Leitner, J. B., Jones, J. M., \& Hehman, E. (2013). Succeeding in the face of stereotype threat: The adaptive role of engagement regulation.
Personality and Social Psychology Bulletin, 39, 17-27. doi:10.1177/0146167212463083

Merten, M. J., Wickrama, K. A. S., \& Williams, A. L. (2008). Adolescent obesity and young adult psychosocial outcomes: Gender and racial differences. Journal of Youth and Adolescence, 37, 1111-1122. doi:10.1007/s10964-008-9281-z

Miller, C. T., Rothblum, E. D., Felicio, D., \& Brand, P. (1995). Compensating for stigma: Obese and nonobese women's reactions to being visible. Personality and Social Psychology Bulletin, 21, 1093-1106. doi:10.1177/01461672952110010

Monda, M., Messina, G., Vicidomini, C., Viggiano, A., Mangoni, C., \& De Luca, B. (2006). Activity of autonomic nervous system is related to body weight in pre-menopausal, but not in post-menopausal women. Nutritional Neuroscience, 9, 141-145. doi:10.1080 10284150600903552

Murray-Close, D. (2011). Autonomic reactivity and romantic relational aggression among female emerging adults: Moderating roles of social and cognitive risk. International Journal of Psychophysiology, 80, 28 35. doi:10.1016/j.ijpsycho.2011.01.007

Myers, A., \& Rosen, J. C. (1999). Obesity stigmatization and coping: Relation to mental health symptoms, body image, and self-esteem. International Journal of Obesity and Related Metabolic Disorders, 23, 221-230. doi:10.1038/sj.ijo.0800765

Nagai, N., \& Moritani, T. (2004). Effect of physical activity on autonomic nervous system function in lean and obese children. International Journal of Obesity, 28, 27-33. doi:10.1038/sj.ijo.0802470

Newman, M. L. (2014). Here we go again: Bullying history and cardiovascular responses to social exclusion. Physiology \& Behavior, 133, 76-80. doi:10.1016/j.physbeh.2014.05.014

Oppenheimer, J. E., Measelle, J. R., Laurent, H. K., \& Ablow, J. C. (2013). Mothers' vagal regulation during the Still-Face Paradigm: Normative reactivity and impact of depression symptoms. Infant Behavior and Development, 36, 255-267. doi:10.1016/j.infbeh.2013.01.003

Palomba, D., Sarlo, M., Angrilli, A., Mini, A., \& Stegagno, L. (2000). Cardiac responses associated with affective processing of unpleasant film stimuli. International Journal of Psychophysiology, 36, 45-57. doi:10.1016/S0167-8760(99)00099-9

Papousek, I., Aydin, N., Lackner, H. K., Weiss, E. M., Bühner, M., Schulter, G., ... Freudenthaler, H. H. (2014). Laughter as a social rejection cue: Gelotophobia and transient cardiac responses to other persons' laughter and insult. Psychophysiology, 51, 1112-1121. doi:10.1111 /psyp. 12259

Penttilä, J., Helminen, A., Jartti, T., Kuusela, T., Huikuri, H. V, Tulppo, M. P., ... Scheinin, H. (2001). Time domain, geometrical and frequency domain analysis of cardiac vagal outflow: Effects of various respiratory patterns. Clinical Physiology, 21, 365-376. doi:10.1046/j.13652281.2001.00337.x

Pessoa, L. (2008). On the relationship between emotion and cognition. Nature Reviews Neuroscience, 9, 148-158. doi:10.1038/nrn2317

Pickett, C. L., \& Gardner, W. L. (2005). The social monitoring system: Enhanced sensitivity to social cues as an adaptive response to social exclusion. In K. D. Williams, J. P. Forgas, \& W. von Hippel (Eds.), The social outcast: Ostracism, social exclusion, rejection, and bullying (pp. 213-226). New York, NY: Psychology Press.

Pila, E., Sabiston, C. M., Brunet, J., Castonguay, A. L., \& O’Loughlin, J. (2015). Do body-related shame and guilt mediate the association between weight status and self-esteem? Journal of Health Psychology, 20, 659-669. doi:10.1177/1359105315573449

Poliakova, N., Després, J.-P., Bergeron, J., Alméras, N., Tremblay, A., \& Poirier, P. (2012). Influence of obesity indices, metabolic parameters and age on cardiac autonomic function in abdominally obese men. Metabolism, 61, 1270-1279. doi:10.1016/j.metabol.2012.02.006

Porges, S. W. (2007). The polyvagal perspective. Biological Psychology, 74, 116-143. doi:10.1016/j.biopsycho.2006.06.009

Puhl, R., \& Brownell, K. D. (2001). Bias, discrimination, and obesity. Obesity Research, 9, 788-805. doi:10.1038/oby.2001.108 
Puhl, R., \& Brownell, K. D. (2003). Ways of coping with obesity stigma: Review and conceptual analysis. Eating Behaviors, 4, 53-78. doi:10.1016/S1471-0153(02)00096-X

Puhl, R. M., \& Luedicke, J. (2012). Weight-based victimization among adolescents in the school setting: Emotional reactions and coping behaviors. Journal of Youth and Adolescence, 41, 27-40. doi:10.1007/s10964-011-9713-z

Puhl, R. M., Moss-Racusin, C. A., Schwartz, M. B., \& Brownell, K. D. (2008). Weight stigmatization and bias reduction: Perspectives of overweight and obese adults. Health Education Research, 23, 347-358. doi:10.1093/her/cym052

Puhl, R. M., Moss-Racusin, C. A., \& Schwartz, M. B. (2007). Internalization of weight bias: Implications for binge eating and emotional well-being. Obesity, 15, 19-23. doi:10.1038/oby.2007.521

Rodríguez-Colón, S. M., Bixler, E. O., Li, X., Vgontzas, A. N., \& Liao, D. (2010). Obesity is associated with impaired cardiac autonomic modulation in children. International Journal of Pediatric Obesity, 6, 128-134. doi:10.3109/17477166.2010.490265

Rosenberg, M. (1965). Society and the adolescent self-image. Princeton, NJ: Princeton University Press.

Schulz, P., \& Schlotz, W. (1999). Trierer Inventar zur Erfassung von chronischem Stress (TICS): Skalenkonstruktion, teststatistische Überprüfung und Validierung der Skala Arbeitsüberlastung. Diagnostica, 45, 8-19. doi:10.1026/0012-1924.45.1.8

Schwartz, M. B., \& Brownell, K. D. (2004). Obesity and body image. Body Image, 1, 43-56. doi:10.1016/S1740-1445(03)00007-X

Seidel, E. M., Silani, G., Metzler, H., Thaler, H., Lamm, C., Gur, R. C., ... Derntl, B. (2013). The impact of social exclusion vs. inclusion on subjective and hormonal reactions in females and males. Psychoneuroendocrinology, 38, 2925-2932. doi:10.1016/j. psyneuen.2013.07.021

Shahrestani, S., Stewart, E. M., Quintana, D. S., Hickie, I. B., \& Guastella, A. J. (2015). Heart rate variability during adolescent and adult social interactions: A meta-analysis. Biological Psychology, 105, 43-50. doi:10.1016/j.biopsycho.2014.12.012

Shelton, J. N. (2005). Expecting to be the target of prejudice: Implications for interethnic interactions. Personality and Social Psychology Bulletin, 31, 1189-1202. doi:10.1177/0146167205274894

Somsen, R. J. M., Van der Molen, M. W., Jennings, J. R., \& van Beek, B. (2000). Wisconsin Card Sorting in adolescents: Analysis of performance, response times and heart rate. Acta Psychologica, 104, 227 257. doi:10.1016/S0001-6918(00)00030-5

Staebler, K., Helbing, E., Rosenbach, C., \& Renneberg, B. (2011). Rejection sensitivity and borderline personality disorder. Clinical Psychology \& Psychotherapy, 18, 275-283. doi:10.1002/cpp.705

Stellar, J. E., Cohen, A., Oveis, C., \& Keltner, D. (2015). Affective and physiological responses to the suffering of others: Compassion and vagal activity. Journal of Personality and Social Psychology, 108, 572-585. doi:10.1037/pspi0000010

Stillman, T. F., Baumeister, R. F., Lambert, N. M., Crescioni, A. W., DeWall, C. N., \& Fincham, F. D. (2009). Alone and without purpose: Life loses meaning following social exclusion. Journal of Experimental Social Psychology, 45, 686-694. doi:10.1016/j. jesp.2009.03.007

Stroud, L. R., Salovey, P., \& Epel, E. S. (2002). Sex differences in stress responses: Social rejection versus achievement stress. Biological Psychiatry, 52, 318-327. doi:10.1016/S0006-3223(02)01333-1

Stunkard, A., \& Mendelson, M. (1967). Obesity and the body image: 1. Characteristics of disturbances in the body image of some obese persons. American Journal of Psychiatry, 123, 1296-1300.

Stunkard, A. J., Sorensen, T., \& Schulsinger, F. (1983). Use of the Danish adoption register for the study of obesity and thinness. In
S. S. Kety, L. P. Rowland, R. L. Sidman, \& S. W. Matthysse (Eds.), The genetics of neurological and psychiatric disorders (pp. 115-120). New York, NY: Raven Press.

Swim, J. K., Cohen, L. L., \& Hyers, L. L. (1998). Experiencing everyday prejudice and discrimination. In J. K. S. C. Stangor (Ed.), Prejudice: The target's perspective (pp. 37-60). San Diego, CA: Academic Press.

Tanaka, H., \& Ikegami, T. (2015). Fear of negative evaluation moderates effects of social exclusion on selective attention to social signs. Cognition and Emotion, 29, 1306-1313. doi:10.1080 /02699931.2014.977848

Thayer, J. F., \& Lane, R. D. (2000). A model of neurovisceral integration in emotion regulation and dysregulation. Journal of Affective Disorders, 61, 201-216. doi:10.1016/S0165-0327(00)00338-4

Thayer, J. F., \& Lane, R. D. (2009). Claude Bernard and the heart-brain connection: Further elaboration of a model of neurovisceral integration. Neuroscience \& Biobehavioral Reviews, 33, 81-88. doi:10.1016/j.neubiorev.2008.08.004

Thompson, J. K., Fabian, L. J., Moulton, D. O., Dunn, M. E., \& Altabe, M. N. (1991). Development and validation of the physical appearance related teasing scale. Journal of Personality Assessment, 56, 513-521. doi:10.1207/s15327752jpa5603_12

Tiggemann, M., \& Kuring, J. K. (2004). The role of body objectification in disordered eating and depressed mood. British Journal of Clinical Psychology/the British Psychological Society, 43, 299-311. doi:10.1348/0144665031752925

Todd, R. M., Cunningham, W. A., Anderson, A. K., \& Thompson, E. (2012). Affect-biased attention as emotion regulation. Trends in Cognitive Sciences, 16, 365-372. doi:10.1016/j.tics.2012.06.003

Tonhajzerova, I., Javorka, M., Trunkvalterova, Z., Chroma, O., Javorkova, J., Lazarova, Z., ... Javorka, K. (2008). Cardiorespiratory interaction and autonomic dysfunction in obesity. Journal of Physiology and Pharmacology, 59, 709-718.

van der Veen, F. M., van der Molen, M. W., Crone, E. A., \& Jennings, J. R. (2004). Phasic heart rate responses to performance feedback in a time production task: Effects of information versus valence. Biological Psychology, 65, 147-161. doi:10.1016/j. biopsycho.2003.07.003

Vanderhasselt, M.-A., Remue, J., Ng, K., Mueller, S., \& De Raedt, R. (2015). The regulation of positive and negative social feedback: A psychophysiological study. Cognitive, Affective, \& Behavioral Neuroscience, 15, 553-563. doi:10.3758/s13415-015-0345-8

Weiner, B., Perry, R. P., \& Magnusson, J. (1988). An attributional analysis of reactions to stigmas. Journal of Personality and Social Psychology, 55, 738-748. doi:10.1177/0146167295215004

Westermann, S., Rief, W., Euteneuer, F., \& Kohlmann, S. (2015). Social exclusion and shame in obesity. Eating Behaviors, 17, 74-76. doi:10.1016/j.eatbeh.2015.01.001

Whittle, S., Yücel, M., Yap, M. B. H., \& Allen, N. B. (2011). Sex differences in the neural correlates of emotion: Evidence from neuroimaging. Biological Psychology, 87, 319-333. doi:10.1016/j. biopsycho.2011.05.003

Will, G.-J., van Lier, P. C., Crone, E., \& Güroğlu, B. (2015). Chronic childhood peer rejection is associated with heightened neural responses to social exclusion during adolescence. Journal of Abnormal Child Psychology, 44, 43-55. doi:10.1007/s10802-0159983-0

Williams, K. D., Cheung, C. K. T., \& Choi, W. (2000). Cyberostracism: Effects of being ignored over the Internet. Journal of Personality and Social Psychology, 79, 748-762. doi:10.1037/00223514.79.5.748 